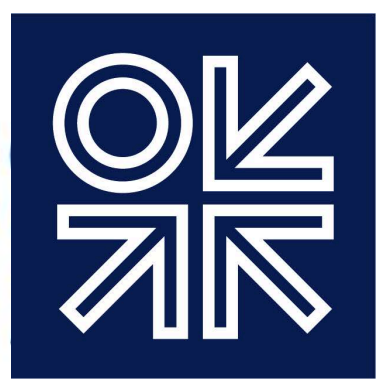

THE OXFORD

INSTITUTE

FOR ENERGY

STUDIES

\title{
The electricity market design for decentralized flexibility sources
}

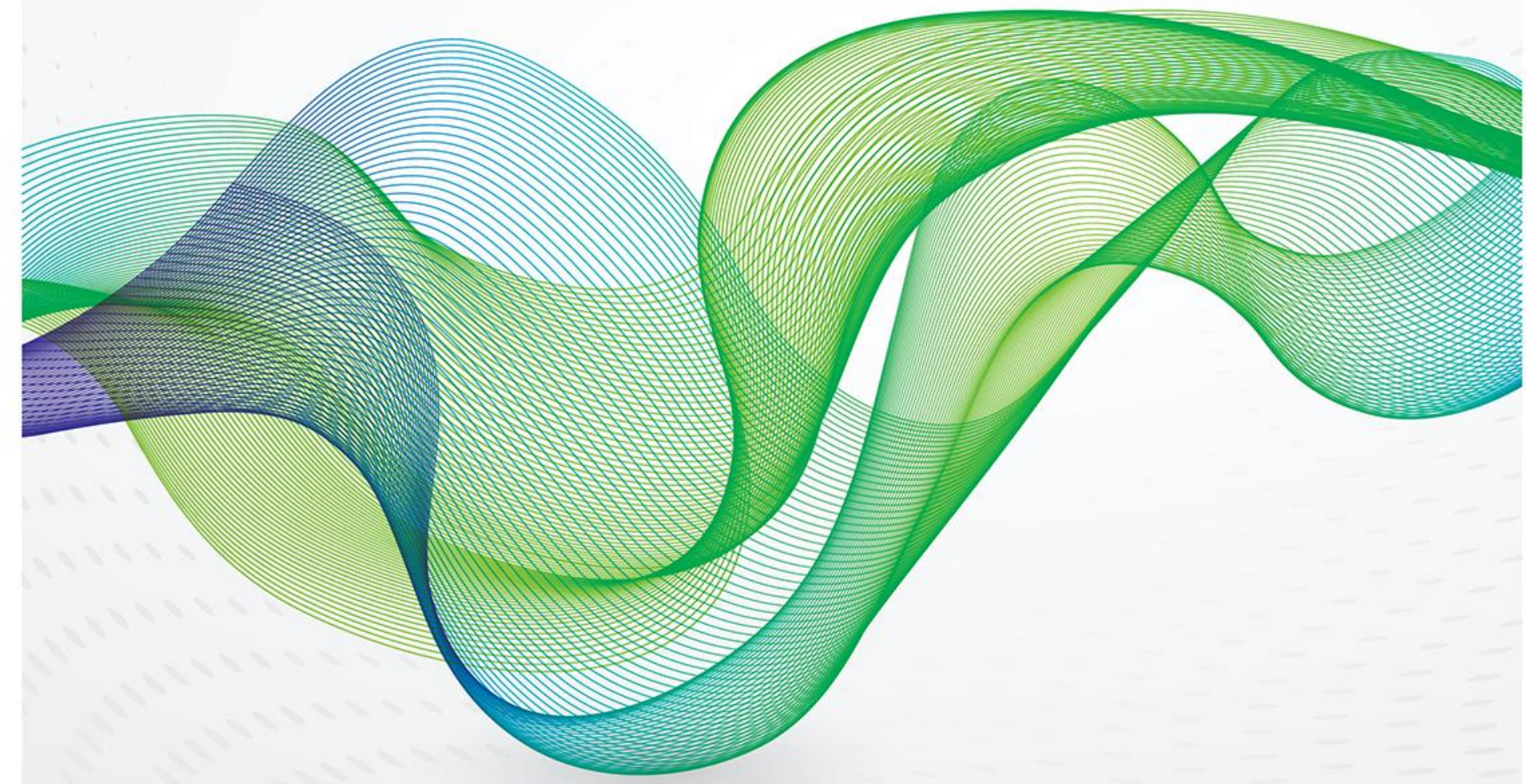



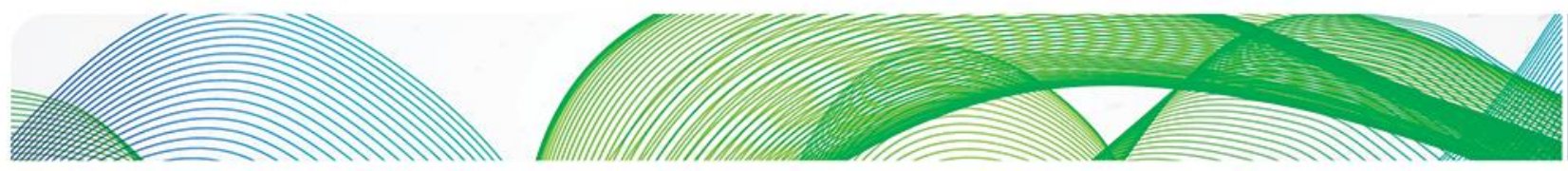

\section{잊조}

The contents of this paper are the author's sole responsibility. They do not necessarily represent the views of the Oxford Institute for Energy Studies or any of its members.

Copyright $\odot 2019$

\section{Oxford Institute for Energy Studies}

(Registered Charity, No. 286084)

This publication may be reproduced in part for educational or non-profit purposes without special permission from the copyright holder, provided acknowledgment of the source is made. No use of this publication may be made for resale or for any other commercial purpose whatsoever without prior permission in writing from the Oxford Institute for Energy Studies.

ISBN 978-1-78467-143-3

DOI: https://doi.org/10.26889/9781784671433 

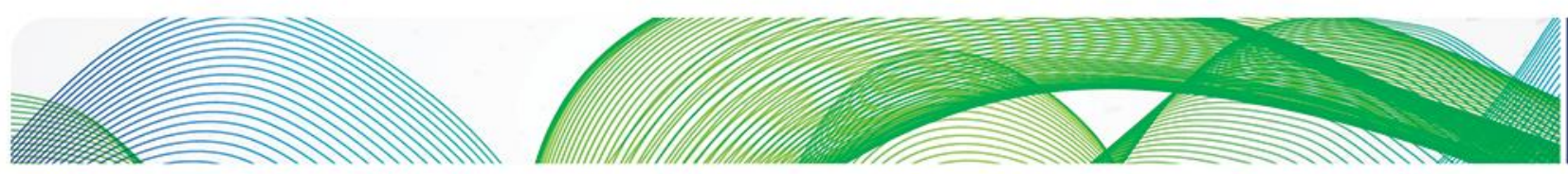

\section{임}

\section{Acknowledgements}

The author would like to thank Rahmat Poudineh, Anupama Sen, David Robinson, Christian Egenhofer, Jaap Jansen for their valuable comments and help during the study. The work also benefited greatly from the discussion and conversation with many experts in the field, particularly Farhad Billimoria, Alexander Scheibe, Milan Elkerbout, Arthur Henriot, Fabio Genoese. The author also appreciates the help from Jo Kemp and Kate Teasdale for editing this paper. Any remaining errors are the author's own responsibility. 


\section{Contents}

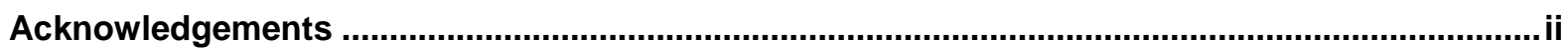

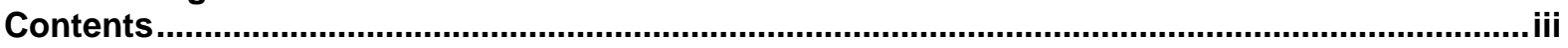

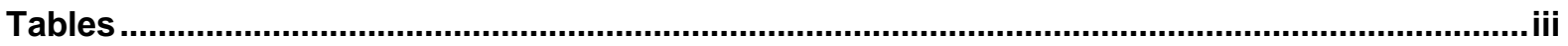

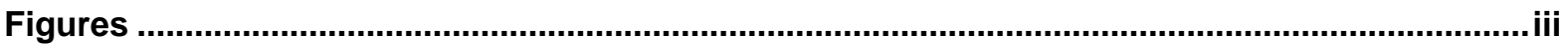

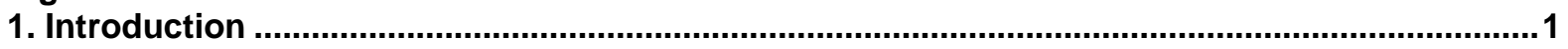

2. The call for sufficient electricity flexibility in the changing electricity system ......................... 2

2.1 Transformation in power systems: Decarbonization, decentralization and digitalization .............2

2.2 Call for sufficient electricity flexibility ...................................................................................

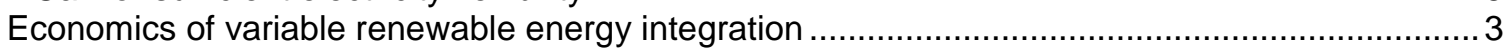

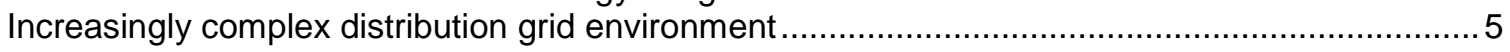

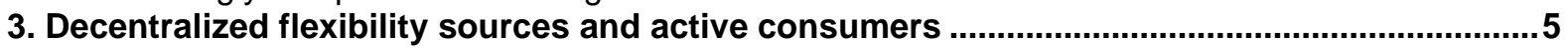

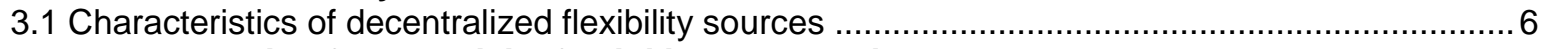

4. The market design for electricity flexibility preservation ........................................................

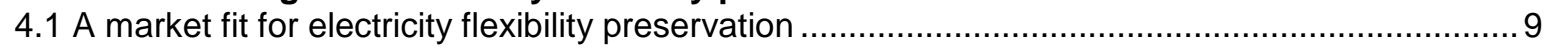

The market for balancing and profile management .............................................................. 9

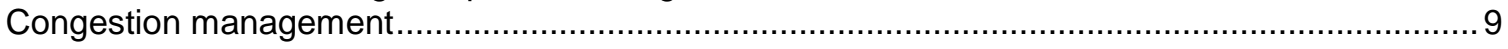

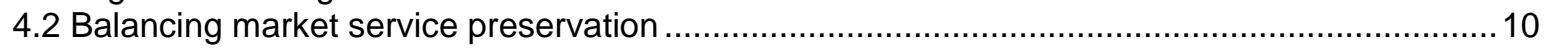

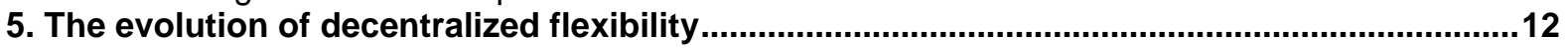

5.1 Decentralized flexibility for demand-side management ...................................................... 12

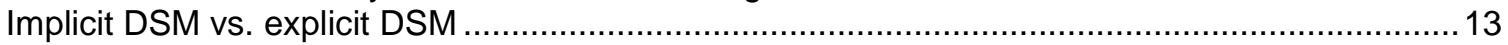

5.2 The market design for decentralized flexibility preservation ............................................... 14

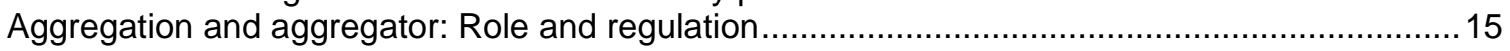

The required market design: Market access ……............................................................. 17

The required market design: Remuneration mechanisms ................................................... 19

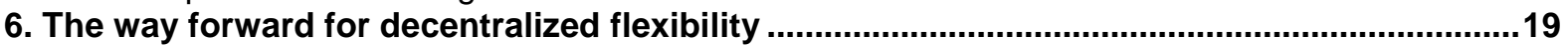

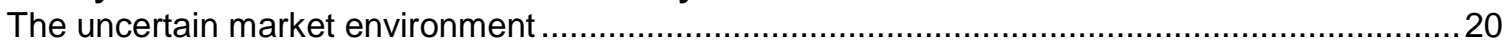

Common vs. customized framework for decentralized flexibility preservation ............................2 20

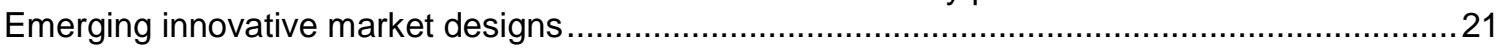

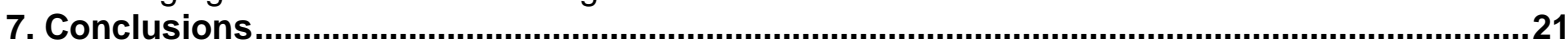

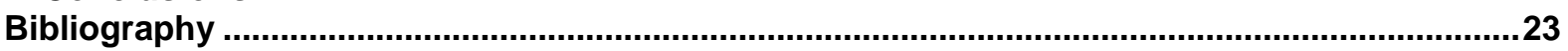

\section{Tables}

Table 1: Explanation of integration costs of variable renewable energy ............................................. 4

Table 2: Identified characteristics for decentralized flexibility sources ............................................ 7

Table 3: Decentralized flexibility resources characteristics illustration ..............................................

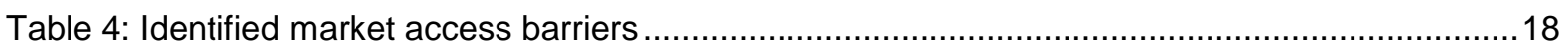

\section{Figures}

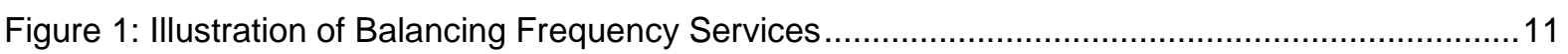

Figure 2: Example of negative services (aFRR) pricing (Austria, 01.05.2018) .................................12 

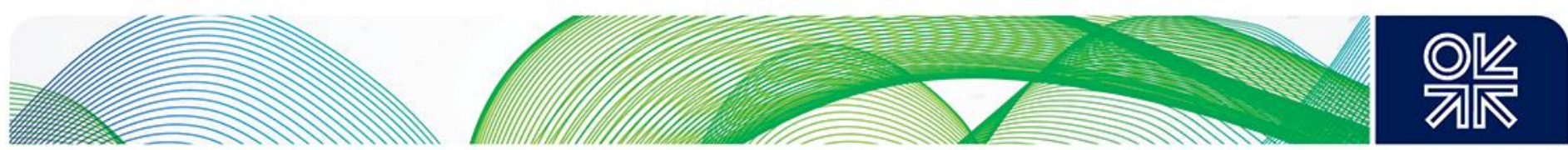

\section{Introduction}

The transformation of the power sector is changing the landscape of electricity supply. With the increasing share of variable renewable energy (VRE) and the increasing complexity of the distribution grid environment, there are rising concerns about whether electricity flexibility will be sufficient to stimulate economic integration of VREs and maintain a reliable grid system. As the discussion of digitalization continues, the potential for decentralized flexibility sources (DFS) to help to maintain a reliable electricity system has caught the attention of policy makers, regulatory bodies and industry groups in Europe. Generally, electricity systems and markets are complex and not always easy to understand. The potential for emerging new markets, services and economic opportunities from DFS is attracting tremendous interest (IEA, 2017b; Agora, 2017; MIT, 2016; EDSO, 2018). However, as the discussion requires an examination of the detail of market design and cross-professional knowledge to understand DFS, the overwhelmingly optimistic public opinion might underestimate the complexity and difficulty of the transformation required.

This paper will try to answer two questions:

1. How can decentralized flexibility sources participate in the electricity markets?

2. What could be the dedicated market design to enable decentralized flexibility?

This paper aims to deconstruct the complexity of electricity market design that could enable decentralized flexibility and shed light on current developments, in an attempt to provide a common understanding for subsequent studies and discussion. Flexibility from decentralized load resources is a young but complex domain. The research and understanding are far from sufficient. This paper will closely reflect what has happened on the ground and foreseen the way forward for continuing research to expand the understanding of the use of DFS within the context of European electricity markets.

The paper concludes that DFS would be more effective as part of an explicit demand-side management (DSM) program rather than an implicit DSM program to stimulate the reliability of the electricity system. Being able to use DFS has strategic importance for VRE integration and achieving decarbonization targets. Moreover, aggregators ${ }^{2}$ play a central role in enabling DFS as they have to actively demonstrate to system operators their ability to deliver the required services. The regulation of aggregators has been largely shaping the current development of DFS. With adequate enabling infrastructures, DFS can participate in existing markets, emerging markets at the distribution level and other potential new products it fits. The emergence of business applications and monetization of DFS depends on many factors, such as broader electricity market design and energy policy, regional resource availability and the penetration level of VRE. Consequently, the pace of development and utilization of DFS will vary between the European member states. The integration of DFS into the electricity market would be more likely to be developed in a decentralized way that starts from areas that require electricity flexibility but lack centralized supply.

This paper starts with a discussion of the demand for sufficient electricity flexibility to allow economical VRE integration and to deal with the increasingly complex distribution grid environment caused by ongoing decarbonization, decentralization and digitalization trends. Then, DFS is properly defined, and different types and characteristics of DFS are illustrated. Next, the electricity markets design is explained and the dedicated market designs for electricity flexibility preservation are elaborated upon. DFS uses for demand-side management (DSM) are explained, different types of DSM mechanisms are justified, and the prevailing way DFS participate in the electricity market is identified. Then, the market designs that allow DFS to participate in the electricity market are discussed. Finally, the future of DFS development is discussed. 

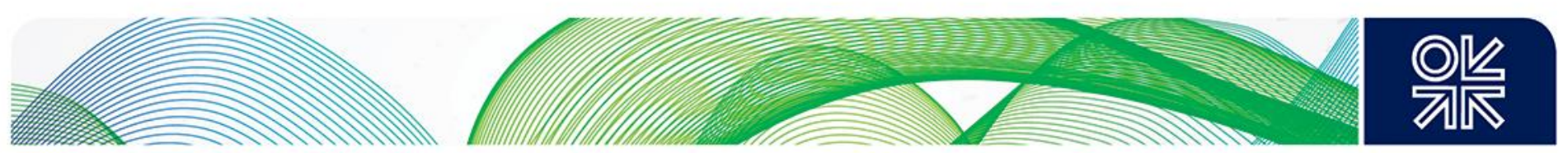

\section{The call for sufficient electricity flexibility in the changing electricity system}

\subsection{Transformation in power systems: Decarbonization, decentralization and digitalization}

The European Union (EU) has committed to reducing greenhouse gas emissions to 80-95 per cent below 1990 levels by 2050. As the power sector has the most significant potential for decarbonization with the decreasing costs of renewable technologies, it is supposed to become carbon neutral by 2050 . The EU 2030 Framework for Climate and Energy, which was adopted in 2014, sets a target of 40 per cent greenhouse gas reduction and at least 27 per cent renewable energy in the final gross consumption of energy by 2030. According to the European Commission Impact Assessment, this target would translate into electricity systems as a 43-47 per cent share of renewables in the power sector and 1214 per cent of renewable energy-based transport by 20303 (EC, 2014). The Renewable Energy Directive adopted in 2018 introduces the requirement to increase the share of energy from renewable sources to 32 per cent in 2030 and allows for the possibility of an upward revision of the target in 2023 $(E C, 2018)$. Achieving the new target would require the share of renewables in the power sector to approach 55 per cent (CAT, 2018). With the decarbonization targets, the landscape of the electricity supply portfolio in the EU has been evolving. Since 2000, the net growth of capacity has been 157.7 GW for wind, 107.3 GW for solar PV and 96.7 GW for gas. In contrast, the observed net reduction in fuel capacity is $40.4 \mathrm{GW}$ for oil-based fuel, $41.2 \mathrm{GW}$ for coal and 17.2 GW for nuclear. Wind energy already has the second-largest power generation capacity in the EU (WindEurope, 2018).

On the other hand, decentralization is making the grid environment increasingly complex. Conventionally, the centralized system is economical as the scale effect brings down average cost. However, the falling price of renewable energy and storage units, with a further boost from increasingly complicated control systems ${ }^{4}$ makes decentralized capacity economically feasible as well. The development of electric vehicles $\left(E s^{5}\right)$ is well on track to achieve long-term sustainability goals. ${ }^{6}$ Although the current stock share of EVs is still low, there is broad consensus that a boom is up-coming ${ }^{7}$ (IEA, 2018b; ExxonMobil, 2018; Eurelectric, 2018). With the rolling out of EVs, the possibility to integrate charging infrastructure to enable smart charging and possible vehicle-to-grid $\left(\mathrm{V}^{2} \mathrm{G}^{8}\right)$ applications can help to reduce overall system costs, stimulate grid reliability and optimize the utilization of grid assets (IEA, 2018a). Such application has been largely supported by governments for technology normalization, for example the City-Zen project in Amsterdam ${ }^{9}$ and a series of V2G projects led by EDF R\&D in the UK ${ }^{10}$ (Gangale et al., 2017; IRENA, IEA \& REN21, 2018). The development of electronic devices and EVs accelerates the learning curve for lithium-ion cells production and enhances the capacities of the industry. Battery costs declined by 15 per cent on average per year from 2012 to 2017, with a total five-year drop of more than 50 per cent (McKinsey, 2018). One likely projection from BNEF (2017) proposed that storage prices would go down from 2017 by a further 63 per cent by 2030, to reach $\$ 70 \mathrm{kWh}$, and the cost of combined household solar with battery system will be comparable with grid electricity after 2025.

\footnotetext{
${ }^{3}$ See COM SWD (2014) 15 final of 22.1.2014, p.68.

${ }^{4}$ Control systems manage and regulate the behaviour of other devices or systems with control loops.

${ }^{5} \mathrm{EV}$ s include battery electric vehicles (BEVs), plug-in hybrid electric vehicles (PHEVs) and fuel-cell electric vehicles (FCEVs).

${ }^{6}$ According to the IEA's Sustainable Development Scenario (2017).

${ }^{7}$ For example, even in Nordic countries, known as the most advanced market in terms of EV sales share, the current EV stock share is only $1.9 \%$. However, Nordic countries are projected to reach 4 million units by 2030 (more than 15-fold of 2017 EVs stock) based on current market development, announced policies and climate ambitions targets (IEA, 2018b).

${ }^{8} \mathrm{~V} 2 \mathrm{G}$ is a bi-directional connection between the EV and the grid through which power can flow from the grid to vehicle and viceversa.

${ }^{9}$ City-Zen project: http://www.cityzen-smartcity.eu/home/demonstration-sites/amsterdam/

10 ' $£ 30$ million investment in revolutionary V2G technologies', 2018: https://www.gov.uk/government/news/30-million-investmentin-revolutionary-v2g-technologies
} 

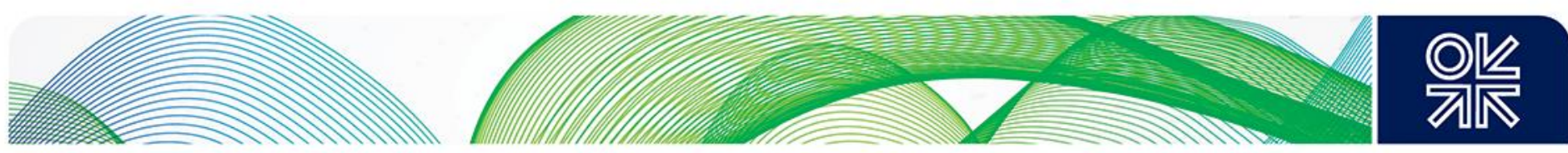

When facing the dynamic from decarbonization and decentralization, the digitalization momentum offers tremendous opportunities. Digitalization plays a significant role in automation applications. The flourishing of Artificial Intelligence (Al) embodied within the energy management system and the further applications of the Internet of Things (IoT) will minimize the input from human users (Glachant \& Rossetto, 2018). The image of a smart energy future has been embraced and discussed by various stakeholders. It pursues the effective aligning of electricity demand and supply with more automation and digitization from all segments of the electricity value chain. By doing so, electricity system could provide services in a high-comfort low-price way and serve political agendas, such as the increase of renewable energy to achieve decarbonization, and reliable supply in a social-cost-effective way (IEA, 2017b; Agora, 2017; MIT, 2016; EDSO, 2018; Rossetto, 2017).

Although digitalization is one of the main trends of today's world power sector, with global investment in digital infrastructure and software reaching nearly $\$ 50$ billion and overtaking global gas-power generation investment in 2016 (IEA, 2017b), gaining a clear understanding of its implications for markets, business models and public policies is an ongoing process. The achievements enabled by digitalization that have been see so far are mainly from operational innovation. As data analytics and automatic decision-making models are being used through machine learning to reduce running costs, efficiency has been improved mainly in electricity system operation (DNV GL, 2018). Nonetheless, the most significant disruption to the existing system would be a potential business model innovation such as person-to-person electricity trading, virtual power plant aggregated from households, etc., with newly available technologies.

There has been an increasingly call for the power system to undergo structural changes to adapt the spread of decentralized components, the digitalization trend and the decarbonization targets. The power sector will need to re-examine the conventional operational model to provide sufficient electricity flexibility in the future.

\subsection{Call for sufficient electricity flexibility}

Flexibility can be defined as the capability of the electric power system to respond to fluctuations and uncertainty in supply and demand to restore stable and safe electricity system operation (DNV GL, 2017; IEA, 2018). It is a property of the whole power system. As storage is negligible in electricity networks, demand and supply need to be balanced at all times, and flexibility needs to cover the fulltime spectrum, from real-time to years long (Mohrhauer, 2016). Conventional flexibility resource includes both flexible consumption and generation resource, and electricity storage and grid interconnection (de Jong et al., 2017). In the past, the demand for flexibility was typically matched by fast-ramping conventional power generation plants through changing load between full load and minimum stable generation. Such plants participate into the different segments of the electricity market after careful consideration of the cost structure for different running states, technical operations and opportunity costs (DNV GL, 2017; Harris, 2005). However, when we consider a fully decarbonized electricity system, there will be no conventional power plants to reserve for the corresponding electrical flexibility requirement. Being able to use decentralized flexibility sources thus has strategic importance for future electricity system. Moreover, there are also concerns for renewable energy integration and requirement from distribution grid management to diversify the flexibility sources.

\section{Economics of variable renewable energy integration}

Wind and solar power are variable renewable energies (VREs). Their power generation fluctuates with the weather patterns. It is different from conventional dispatchable power capacities (coal, gas, nuclear and hydropower generation), where generators can supply energy on demand and have relatively more controllability of generation. Nowadays, even the countries with the highest share of VRE in Europe only have a penetration level of around 40 per cent and the vast majority still only have a VRE penetration level of around 20 per cent (IEA, 2018). Considering the 2050 decarbonization targets, a carbon-neutral electricity sector would have a significantly higher share of VRE generation. 

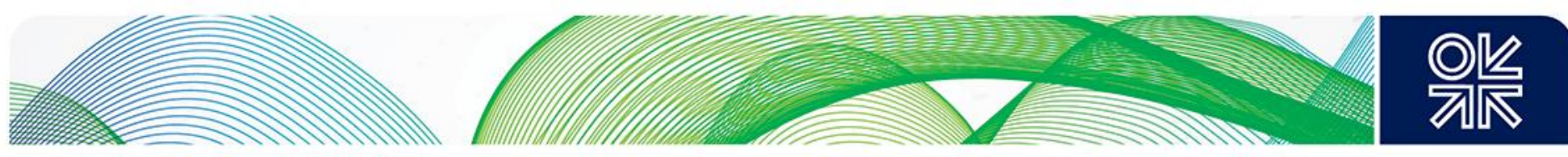

With the increasing penetration of VRE, flexibility has been a valuable characteristic appreciated by the electricity system. The VRE would have a lower contribution to covering forecast electricity demand and especially the peak demand when the capacity is most needed. Meanwhile, VREs need extra dispatchable energy that has the capacity to ramp and decline with short lead times and cool-down times to respond to their variability and potential forecast errors (IEA, 2018a; Hesser \& Succar, 2012). The uncertainty of output increases the amount of holding reserve capacity and induces extra cost. Moreover, for renewable-based electricity systems, the seasonal variation of energy generation would require a significant amount of reserve capacity, the cost of which should be minimized.

The integration cost of VRE can be defined as all additional costs in the non-VRE part of the power system during the generation of VRE (Hirth, 2013; Ueckerdt et al., 2013). It encompasses subcategories as profile costs, balancing costs and grid-related cost.

\section{Table 1: Explanation of integration costs of variable renewable energy}

\begin{tabular}{|l|l|}
\hline Profile costs & $\begin{array}{l}\text { The profile costs consist of three components: overproduction costs, full-load } \\
\text { hour reduction costs and adequacy costs. } \\
\text { Overproduction costs: A high share of VRE would cause curtailment, causing } \\
\text { per-energy costs of VRE to increase. }\end{array}$ \\
\hline Balancing costs & $\begin{array}{l}\text { Full-load hour reduction: The reduction of full-load running hours for } \\
\text { dispatchable power plants would reduce its electricity generation and thus } \\
\text { increase per-energy costs for dispatchable power plants. } \\
\text { Adequacy costs: VRE would increase the demand for backup capacity as they } \\
\text { are highly weather dependent (not for balancing purposes, but for resource } \\
\text { adequacy purposes). }\end{array}$ \\
\hline Grid-related costs & $\begin{array}{l}\text { Balancing costs are the added system costs for holding and using resources } \\
\text { to deal with forecast errors and variability during dispatch intervals, as well as } \\
\text { increased ramping and cycling of other power plants. It highly depends on } \\
\text { operational practices, such as the use of forecasts and market arrangements. }\end{array}$ \\
\hline $\begin{array}{l}\text { Grid-related costs are the rising costs from the extra care for grid management } \\
\text { because of the increasing penetration of VRE generation. }\end{array}$ \\
\hline
\end{tabular}

Sources: Ueckerdt et al., 2013; IEA\&NEA, 2015

The integration cost will increase with a growing level of VRE penetration. The profile costs are potentially the largest component. Any means that can help to shift demand or supply would significantly reduce the profile costs (Ueckerdt et al., 2013). Once the marginal externalities that are caused by VRE integration are equal to the marginal utility of energy sector decarbonization, further decarbonization of the energy sector would make no sense. Although there are no effective ways to calculate marginal externalities and decarbonization utility in reality, the negative electricity price caused by VRE and unexpected curtailment of VRE generation would be signs. Thus, for the sake of realizing decarbonization targets, the externalities caused by VRE should be minimized systematically. An economical energy transformation implies gaining as much efficiency from operation and management as possible while minimizing VRE integration costs (EDSO, 2018). Practically, minimizing these costs means the practical use of installed electricity capacities, such as reducing the curtailment of VRE generation, ensuring profitable load factors of dispatchable units, minimizing the cost of system balancing and reserves. All those necessities call for sufficient electricity flexibility. 

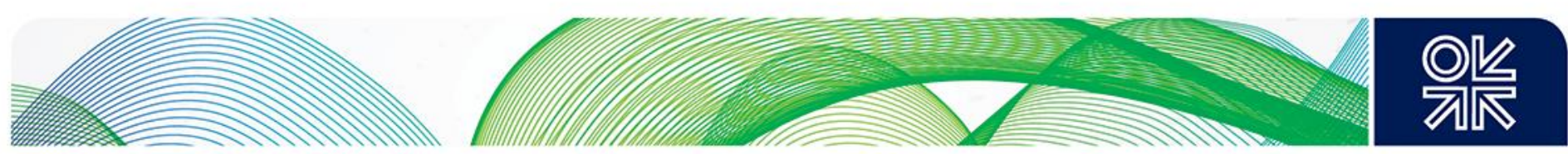

\section{Increasingly complex distribution grid environment}

With the majority of VRE capacities connected to the transmission grid, congestion and local saturation of distribution grids require distribution system operators (DSOs) to become more active. The increasingly complex distribution grid environment requires more accurate and granulate management decisions. Further challenges arise from the complexity of existing systems and the high public expectations of safety and reliability.

DSOs are responsible for expanding, reinforcing and maintaining the safety and reliability of the distribution grid system (DNV GL, 2018; Poudineh \& Jamasb, 2014). The existing grid management and system balancing formulas are developed in the context of centralized production and distribution of energy (Frunt, 2011; IEC, 2012). However, nowadays, most VRE capacities and EV charging stations are connecting at the distribution level (de Jong et al., 2017; Newbery et al., 2017). The evolving of 'behind-the-meter' generation, the change from unidirectional to bi-directional electricity flow, and the development of EVs and local energy communities all increase the chance of local congestion, which will require DSOs to move away from the conventional approach and become active in balancing their grid system (Meeus \& Hadush, 2016). Moreover, the current reserves and flexibility preservation are only the responsibility of Transmission System Operators (TSOs). Gradually, the reserves will be essential for all stakeholders who could not carry on their business without reliable supply (Lavoine, 2018; Rossetto, 2017; DNV GL, 2017).

Currently, the framework of active distribution network management for DSOs is still unclear (Meeus \& Nouicer, 2018). The collaboration between TSOs and DSOs with regard to active system management and the use of decentralized energy resources has been identified as the main priority of the EU (ENTSO-E, 2018). Operation protocols and seamless communications are required between DSOs and TSOs to ensure optimal system operation and to eliminate counterproductive behaviour. Previously, there was limited interaction between TSOs and DSOs in terms of acquiring electricity flexibility (Gerard et al., 2018). Prior coordination between TSOs and DSOs only concerns network planning, common data platforms or metering data sharing (de Jong et al., 2016; Hadush \& Meeus, 2017). The model of coordination between DSOs and TSOs will lead to different market designs and system services. Specific concerns such as distortionary aggregation, active data exchange and system prequalification need to be addressed in a proper way (Burger et al., 2016). Micro-grids and energy communities may able to pre-balance themselves but still need to connect with the public grid for back-up (USEF, 2015). Notably, increasing VRE penetration at the distribution level will lead to a considerable amount of local demand for ancillary services, which should be satisfied by similar market design (Merion et al., 2016). All these transformations require considerable electricity flexibility at both transmission and distribution grids and revision of the current electricity system management mechanism.

\section{Decentralized flexibility sources and active consumers}

Increasing the number of active consumers has been one of the aims of the EU's energy union strategy. In European Commission official documents, the terms active customers, active consumers and prosumers are used with the same meaning (Meeus \& Nouicer, 2018). The definition of the active consumer can vary to emphasize different customer groups. It has been defined by Meeus and Nouicer (2018) as electricity consumers that are engaged in the consumption and production of electricity, and also other roles such as storage and demand response. The definition of prosumer is more straightforward: the end user who can produce energy (USEF, 2015).

In this study, the active consumer is defined following Merino and her colleagues (2016) as technologically empowered end-users who are able to present their desire for energy management. This customer group is recognized as the residential sector and includes residential consumers, small and medium-sized enterprises (USEF, 2015). Their activity in terms of energy management decisions includes demand response from household appliances, household and local community battery management, electric vehicle charging management, energy storage in non-electrical form - heat, cold, 

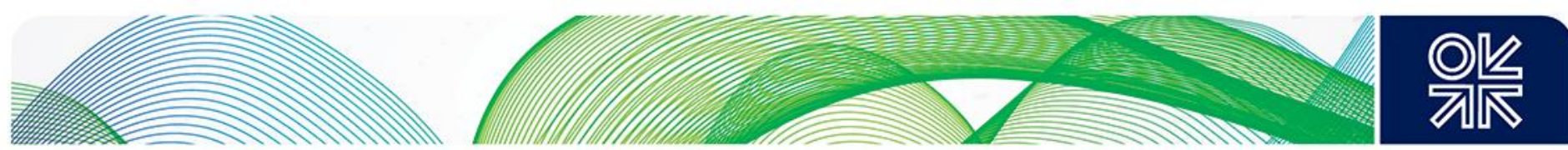

pressure, etc. - and some industrial processes (Rossetto, 2017; Verhaegen \& Dierckxsens, 2016). These activities were previously known as residential demand response and are acknowledged today as decentralized flexibility sources. These residential resources that can provide electricity flexibility services are referred to as decentralized flexibility sources (DFS) in this study.

Theoretically, the residential sector has considerable flexibility potential which has not been realized primarily because of technological limitations (EC, 2016a; Sia Partners, 2014). Nowadays, these capacities have the potential to be empowered by advanced information technology and communication infrastructure, which allows them to auto-optimize their load in a fast and accurate way according to electricity availability (ENTSO-E, 2019). On the other hand, decentralized flexibility also includes the flexibility from decentralized generation resources, such as Micro-CHP units and state-of-the-art VRE, ${ }^{11}$ but this paper will only focus on demand-side resources (IEA, 2018; IRENA, IEA \& REN21, 2018; CEPA, 2014).

\subsection{Characteristics of decentralized flexibility sources}

The key feature of the residential sector is the diversity of appliances. Decentralized flexibility sources (DFS) are comprised of different load sources with a wider variety of technical capabilities and economic characteristics to provide flexibility services (Migliavacca et al., 2017; Eid et al.,2016). For different kinds of appliances, the costs to enable the services and the corresponding opportunity costs are different. ${ }^{12}$ Appliances with large loads and less time-sensitivity, ${ }^{13}$ such as space heating/cooling and vehicle charging, would be reasonable resources to begin to participate in active management programs (Darby \& McKenna, 2012; Goldenberg et al., 2018). All those appliances have to be examined and differentiated because different DFS require different types of regulations, support, delivery methods and communication techniques for the most effective way to facilitate the program. Different types of resources may desire participating in different markets according to their resource characteristics. For example, EVs would suit providing short-term flexibility services, as the opportunity costs would increase substantially once EVs are aggregated and start providing bulk energy to markets (Borne et al., 2018).

Eid et al. (2016) gave an overview of common DFS under no aggregation circumstances. Four characteristics are used to illustrate a DFS: direction, energy/power characteristics, response time and availability.

\footnotetext{
11 VRE capacity uses software-controlled power electronics to connect to the grid and can provide multiple services to manage the variability and uncertainty of supply and demand. For example, through blade pitching, wind turbines can provide an upward and downward reserve. In Spain, since Feb 2016, wind energy is allowed to provide ancillary services.

12 For demand-side resources. It would be reasonable to use opportunity costs to reflect the economic value instead of marginal costs (CE Delf \& Microeconomix, 2016).

${ }^{13}$ Less time-sensitivity indicates less opportunity cost.
} 

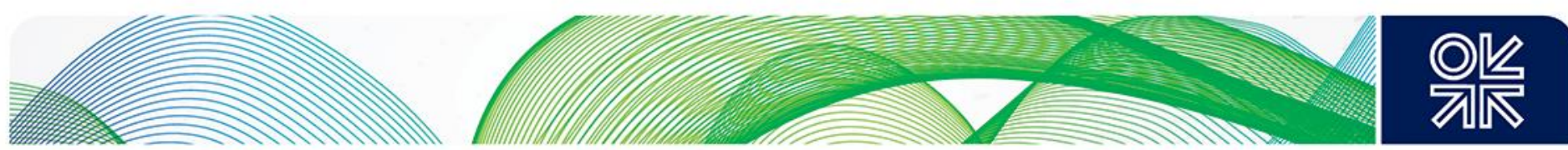

Table 2: Identified characteristics for decentralized flexibility sources

\begin{tabular}{|l|l|}
\hline Characteristics & \multicolumn{1}{c|}{ Description } \\
\hline Direction & $\begin{array}{l}\text { System operators need to procure both upwards and downwards } \\
\text { balancing resources (Burger et al., 2016). Meanwhile, specific appliances } \\
\text { may only be capable of providing either upwards or downwards services. }\end{array}$ \\
\hline Energy/Power type & $\begin{array}{l}\text { DSM programs have two types of applications: energy applications and } \\
\text { power applications. Typical energy applications refer to load shifting and } \\
\text { typical power applications to things such as frequency control and ramp } \\
\text { rate control (WEC, 2016; EnerNOC, 2011). Eid et al. (2016) defined max } \\
\text { power temporal ratio (tr) as the maximum duration a DFS can sustain its } \\
\text { maximum power variation concerning its normal power. This parameter } \\
\text { is to justify the energy/power type and indicate the potential ancillary } \\
\text { services a DFS can provide. The lower the parameter value, the more the } \\
\text { resource can be classified as a power type. }\end{array}$ \\
\hline Response time & $\begin{array}{l}\text { Response time indicates how quickly a resource is technically able to } \\
\text { adjust its power and can be used to compare with the notification time for } \\
\text { market requirements. It should be shorter than the service notification } \\
\text { time to participate in corresponding markets. }\end{array}$ \\
\hline Availability & $\begin{array}{l}\text { DFS are not dedicated to DSM. Eid et al. (2016) defined the parameter } \\
\text { ar, the average number of available hours divided by the total number of } \\
\text { hours in a week, as a parameter to quantify resource availability (0< ar } \\
\text { <1). Nevertheless, the specific time DFS are available may be more } \\
\text { critical to provide appropriate service. }\end{array}$ \\
\hline
\end{tabular}



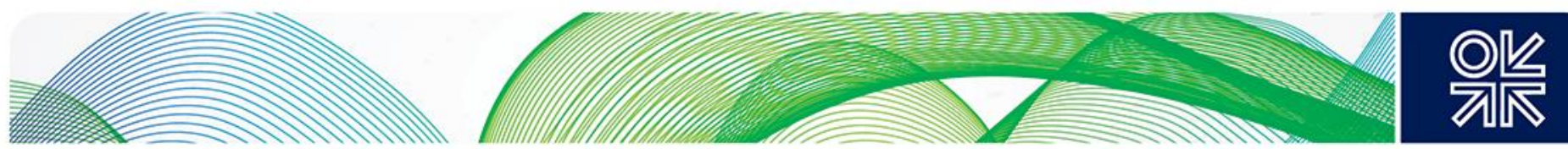

Table 3: Decentralized flexibility resources characteristics illustration

\begin{tabular}{|c|c|c|c|c|}
\hline Type of DFS & Flexibility direction & $\begin{array}{l}\text { Flexibility characteristic (power vs } \\
\text { energy) }\end{array}$ & Availability ratio & $\begin{array}{l}\text { Technical required } \\
\text { response time }\end{array}$ \\
\hline $\begin{array}{l}\text { Residential loads (washing } \\
\text { machine, dishwashers) }\end{array}$ & $\begin{array}{l}\text { Unidirectional } \\
\text { (downwards or } \\
\text { upwards) }\end{array}$ & $\begin{array}{l}\text { Power type: } \\
5 s<t<5 \text { min }\end{array}$ & $a_{r}<0.1$ due to high off time & Seconds \\
\hline $\begin{array}{l}\text { Residential continuous loads } \\
\text { (electrical heating and cooling + } \\
\text { potential storage) }\end{array}$ & Bidirectional & Power type: $\mathrm{t}_{\mathrm{r}} \approx 15 \mathrm{~min}$ & $0.4<a_{\mathrm{r}}<1$ & Seconds \\
\hline $\begin{array}{l}\text { Electrochemical energy storage } \\
\text { (kW-MW) }\end{array}$ & Bidirectional & Power and energy type: $4 \mathrm{~s}<\mathrm{t}_{\mathrm{r}}<10 \mathrm{~h}$ & $a_{\mathrm{r}} \approx 1$ & Seconds \\
\hline Electric vehicle & $\begin{array}{l}\text { Unidirectional } \\
\text { (downwards) or } \\
\text { bidirectional }\end{array}$ & Power and energy type: $30 \mathrm{~min}<\mathrm{t}<6 \mathrm{~h}$ & $0.5<a_{r}<0.9$ & Seconds \\
\hline Public lighting loads & $\begin{array}{l}\text { Unidirectional } \\
\text { (downward) }\end{array}$ & $\begin{array}{c}\text { New LED systems: Energy type } \\
\text { Older lighting: Power type }\end{array}$ & $0.2<\mathrm{a}_{\mathrm{r}}<0.5$ during peak hours & Seconds \\
\hline
\end{tabular}

Source: adapted from Eid et al. (2016).

\section{The market design for electricity flexibility preservation}

In the liberalized power system, the demand for electricity flexibility is secured with appropriate electricity market designs. Although, the term 'market' is used ambiguously. In reality, any single product or service defined by the system operator or market operator can be considered as an independent market in the electricity sector. Electricity resource can participate among different markets follow defined rules to maximize their profit. To allow the use of decentralized flexibility, corresponding market arrangements and product design would be required. The current market design should be understood before introducing the potential use of decentralized flexibility.

The market arrangements are different in the different European Union member states (MSs). Nevertheless, the fundamental market structures, including a series of forwarding markets and balancing markets, are the same. Market design concerns the operation to manage economic transactions and operational control mechanisms (Eid et al., 2016a). Specific market design creates corresponding incentives for market agents to react (CE Delf \& Microeconomix, 2016). In general, electricity prices are the critical incentive for demand and supply inter-alignment, which was the initial rationality to expose electricity to spot market prices. Power producers and other market participants would react to price signals by adjusting their power output level or trade in according markets (Couture et al., 2015; Redl, 2018; Schittekatte \& Meeus, 2018a; DNV GL, 2017). In many MSs, there is also a capacity mechanism alongside the energy-only market to guarantee electricity resource adequacy (EC, 2015). 

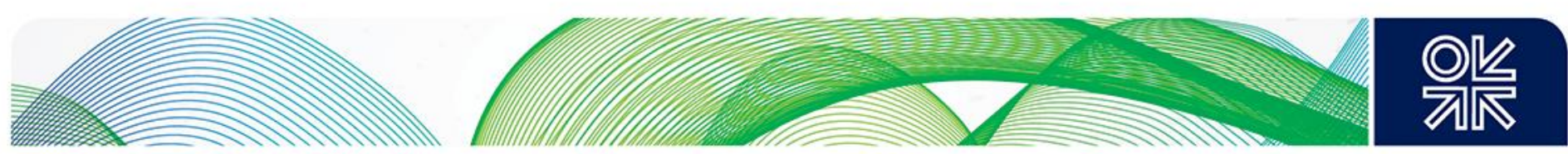

\subsection{A market fit for electricity flexibility preservation}

Electricity flexibility is needed for system balancing, profile management and grid congestion management. The markets are designed correspondingly to satisfy these demands for electricity flexibility.

\section{The market for balancing and profile management}

Various forms of trading help market agents to manage their profile and help system operators to balance their grid. Different forward electricity markets are arranged in sequential orders to deal with the variability of different timescales and facilitate market participants' profile management up until 1560 minutes prior to the time of consumption (IEA, 2018; DNV GL, 2017; Zancanella \& Bertoldi, 2017). Market participants trade in different markets according to their requirement to hedge their risks in the real-time spot market and avoid imbalance charges (USEF, 2015). The typical short-term markets that serve profile management functions most effectively are the day-ahead market and the intraday market. These markets remunerate flexibility according to whether any power resource can change its energy level approaching real-time (CE Delft \& Microeconomix, 2016).

\section{Congestion management}

Congestion happens mainly due to mismatches between market outcome and network status, as power would not follow the contracted path directly (Hadush \& Meeus, 2017). The market designs for the wholesale market to deal with congestion depend on the applied system pricing model.

There are zonal pricing models and nodal pricing models (Mohrhauer, 2016). Nodal pricing is also known as the locational marginal pricing (LMP) model. Any congestion in a nodal pricing market would lead to differences in marginal electricity prices at every node, reflecting the lack of generation capacity and transmission capacity. Consumers at a high-priced node have an incentive to reduce demand. In the end, all accepted energy and load offers are paid at a local uniform price associated with each node of the electricity market. Consequently, it gives a generation schedule without requiring further capacity alleviation (Mohrhauer, 2016). On the other hand, the use of the zonal model trades efficiency for simplicity because the nodal pricing model design is far more complex (Holmberg \& Lazarczyk, 2012). Zonal pricing only considers transmission constraints among zones and assumes a uniform marginal price within one zone. Under the zonal model, the principal approach to relieve grid congestion is redispatch. Re-dispatch is defined as any measures activated by system operators to adjust the generation or load pattern in order to change physical flows in the power system and relieve physical congestion (ACER \& CEER, 2016; Hadush \& Meeus, 2017). Sometimes, Transmission System Operators (TSOs) also use the balancing market to preserve resources to relieve congestion ${ }^{14}$ as long as the bids provide necessary locational information (EDSO, 2018). The difference is that the system imbalance cost is mainly borne by Balancing Responsible Parties (BRPs) and the re-dispatch cost is mostly financed by grid tariffs (Hadush \& Meeus, 2017). Otherwise, there would be other dedicated markets, products or arrangements to allow the system operator to preserve the necessary electrical energy to relieve grid congestion in real-time (EDSO, 2018).

The European electricity market is a zonal system. All bidding zones are connected through transmission lines and interconnectors. Within each bidding zone, the congestion is relieved through re-dispatching by corresponding TSOs. Between each bidding zone, the implicit cross-zonal transmission capacity allocation mechanism has been applied to reflect the scarceness of transmission capacity, and counter trading is operated by system operators between two bidding zones to relieve physical congestion (Schittekatte \& Meeus, 2018a; ENTSO-E, 2019).

\footnotetext{
${ }^{14}$ Network congestion and system balancing are addressed at the same time.
} 

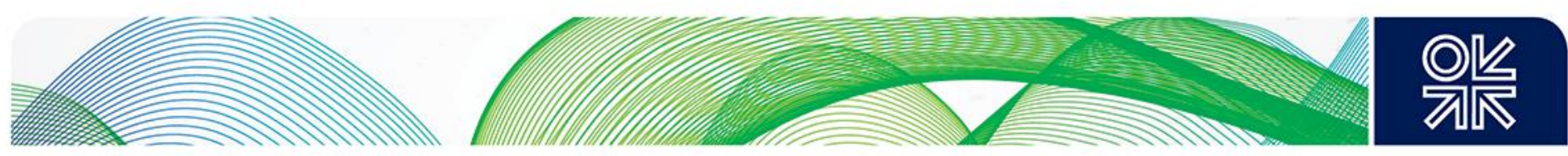

\subsection{Balancing market service preservation}

The balancing market is the 'market of last resort' for balancing the electricity system (Redl, 2018). It is also the market that is the most suitable for incorporating decentralized flexibility, considering that most DFSs are more economically competitive in providing short-term flexibility services. The balancing market represents the entire institutional, commercial and operational arrangement that enables a market-based balancing of the electricity system. This real-time balancing price has a substantial impact on prices in the wholesale electricity markets. It reflects the ultimate opportunity cost for any trading conducted before real-time (Hogan, 2015; Mauritzen, 2013).

The balancing market serves as the tool to help TSOs preserve flexibility resource and enable responsibility sharing with BRPs. The balancing responsibility mechanism is a secondary control mechanism invented to share the balancing burden on TSOs through an economic and financial mechanism (Frunt, 2011). Theoretically, every agent connected to the grid has to share the balancing responsibility, which means the agent should try to react in real-time in line with their forecast or reported position. Currently, household consumers let retailers be in charge of their balancing responsibility. Retailers can take the responsibility themselves or pass it on to another party (a BRP) with extra arrangements (Mandatova \& Mikhailova, 2014). The cost of maintaining the balancing responsibility by retailers is recovered through relative contractual arrangements with final consumers (Schittekatte \& Meeus, 2018a; USEF, 2015). Previously, VRE generators were exempted from balancing responsibility.

The balancing cost is shared among BRPs using the imbalance settlement mechanism (Schittekatte \& Meeus, 2018a; ENTSO-E, 2018a). Imbalance settlements refer to how imbalance quantity and price are determined, and how the imbalance costs are allocated. It provides special incentives for market participants to interact with the market (Burger, 2016). Imbalance pricing is done within a specific timeframe, the imbalance settlement period (ISP). In the European Union, countries currently apply ISPs of 60,30 and 15 minutes. A shorter ISP could contribute to a more cost-reflective imbalance pricing. For example, with 30 minutes ISP, the generator could overshoot during the first 15 minutes and undershoot during the second 15 minutes. Overall, it can count as balanced as the counteractions offset each other within that ISP. With a shorter ISP, like 15 minutes, BRPs have to manage their profile more wisely to balance their position (Merino et al., 2016). The electricity balancing guideline requires all TSOs to harmonize the ISP by 2021 , or at the latest by 2025, to an ISP of 15 minutes (ENTSO-E, 2018a). For different MSs, TSOs currently use different imbalance settlement mechanisms. For example, Belgium applies a single price scheme and the Netherlands use a hybrid pricing scheme which changes between single and dual pricing. ${ }^{15}$ Generally, BRPs are encouraged to act against system imbalances. If the system has a positive imbalance, then a negative imbalance from BRP will be remunerated. If the system has a negative imbalance, then a positive imbalance from BRPs will be remunerated through an imbalance settlement. In case of non-delivery of any service, it would be counted as an imbalance and corresponding imbalance costs are allocated to the corresponding party. To minimize the incentive of non-delivery, normally, an extra penalty scheme also applied (Elia, 2017).

Because the European synchronous area is interconnected, any unexpected failure would impact the pan-European power system. ENTSO-E offers a framework for the Load-Frequency-Control processes that national implementation must adhere to in order to satisfy the minimum requirements of the ENTSO-E guideline (Merion et al., 2016; MacDonald, 2013). Arrangements for different TSOs may be diverse as those arrangements have to be in line with national and local specificities. ${ }^{16}$ European TSOs have adopted different processes and products based on historical developments and different balancing philosophies (ENTSO-E, 2018a). Thus, there are a great variety of market designs exist with

\footnotetext{
${ }^{15}$ Single pricing indicates that the price for a negative imbalance (facilitating system balancing) is the same as the price for a positive imbalance (against system balancing). Duel pricing indicates that both directions of imbalance have a different price. Single pricing asks BRPs to balance their profile according to their reported position. Duel pricing provides incentives to BRPs to react to system imbalance.

${ }^{16}$ Parameters can be the level of congestion and generation profiles.
} 

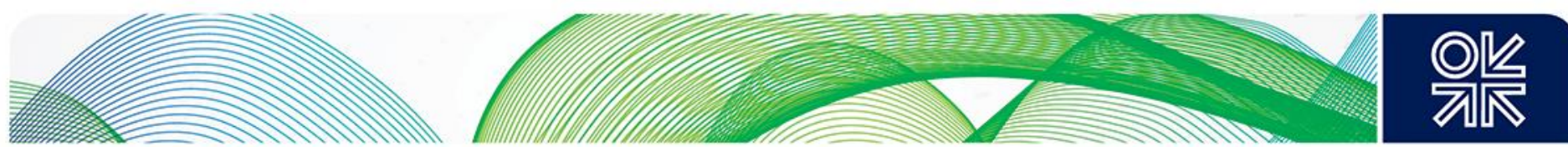

respect to pre-qualification requirements, bid evaluation and settlement rules of standardized service (Klessmann et al., 2008). TSOs name the services, define common balancing methodologies and operational protocols, and determine what the sufficient amount of reserve capacity is through various technical criteria within their control areas (ENTSO-E, 2018a; MacDonald, 2013). If an imbalance occurs very close to real-time, the TSO has to instruct resources, termed Balancing Service Providers (BSP), to reduce or raise their generation or load in order to restore the system balance (Schittekatte \& Meeus, 2018a; DNV GL, 2017).

Balancing services, in some circumstances also known as ancillary services, ${ }^{17}$ conduct product design and flexible resource preservation according to system voltage and frequency requirements (Frunt, 2011). According to the ENTSO-E framework, the services that are utilized by TSOs for frequency control are Frequency Containment Reserve (FCR), Frequency Restoration Reserve (FRR) and Replacement Reserves (RR). FCR is an initial and automatic response to imbalances; FRR and RR are used to supplant the use of FCR. There are further classifications for FRR as aFRR (automatic activation) and mFRR (manual activation). When an imbalance occurs, the activation follows sequential rules since the capacities that have the shorter response time are usually the more expensive and need to be replaced successively. There are also extra voltage control reserves to provide sufficient reactive power $^{18}$ (MacDonald, 2013; Merino et al., 2016; Zancanella \& Bertoldi, 2017). There is a notification time for each service, and the notification acts as a signal that service providers are ready to undertake the action. Using the French market as an example, FCR is notified 30 seconds before real-time, FRR is notified 15 minutes before action and RR would normally be between 15 minutes and 2 hours before real-time. Because of their short notification time, FCR and aFRR services are required to be automated (Eid et al., 2016).

Figure 1: Illustration of Balancing Frequency Services

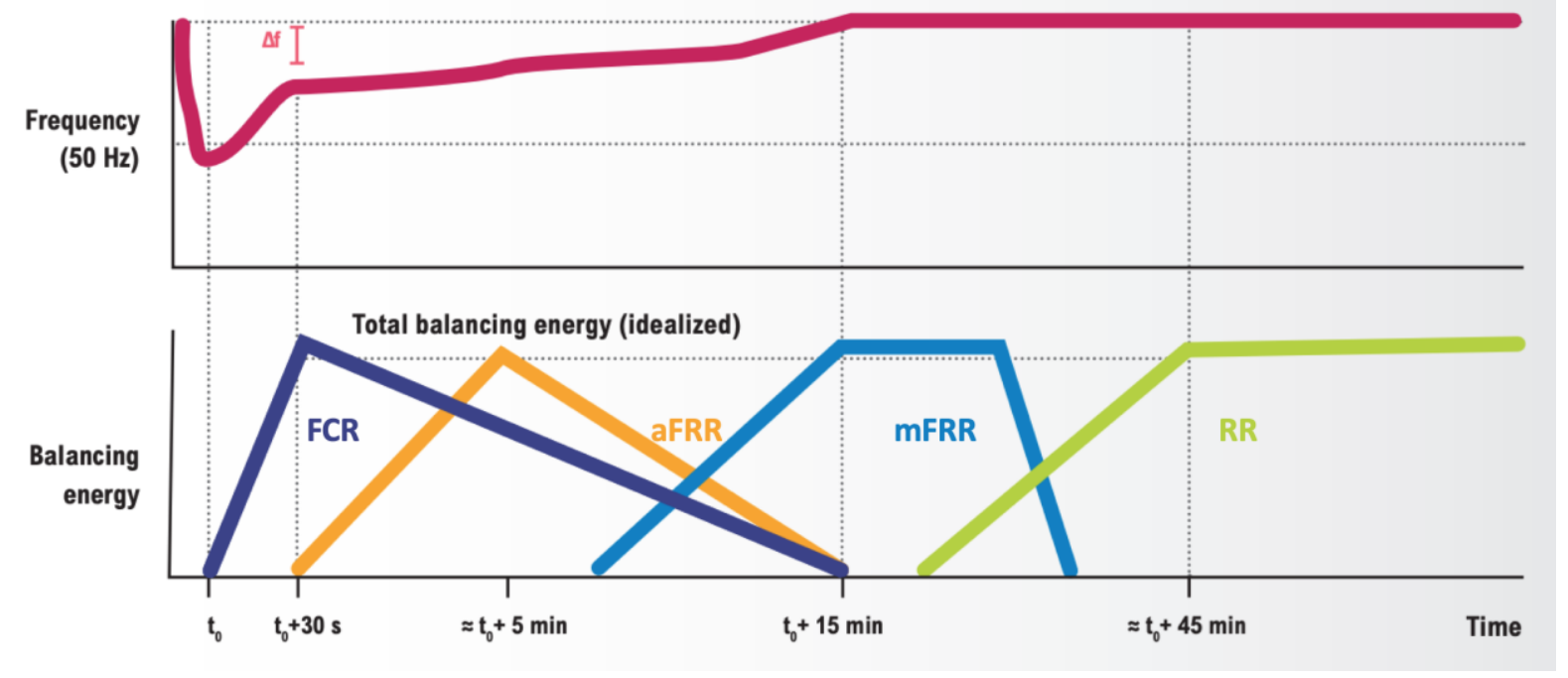

Source: ENTSO-E, 2018

The provision of balancing services by the balancing market could be categorized into two groups according to the provision time: balancing reserves (capacity, MW) and balancing energy (energy, $\mathrm{MWh}$ ). The balancing reserves are capacity procured in advance and activated in real-time when encountering imbalance. The balancing energy is the energy activated by TSOs to maintain the balance of the system in real-time (MacDonald, 2013; Schittekatte \& Meeus, 2018a).

\footnotetext{
17 'Ancillary services' is a more generic term including other system services such as black start, grid loss compensation etc.

${ }^{18}$ The voltage control reserves have a local character and depend on the grid topologies.
} 

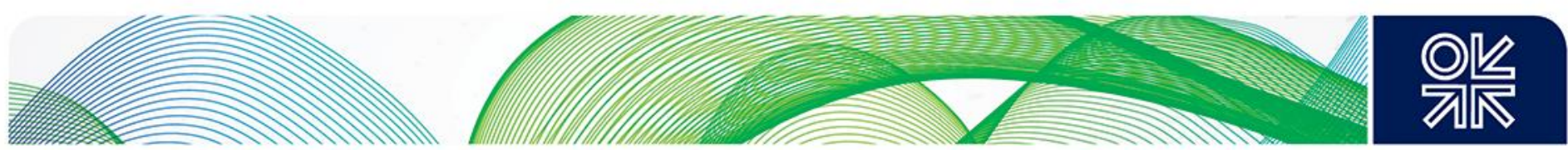

1. Balancing capacity/reserve market: TSOs buys the reserve capacities in advanced (from dayahead to year-ahead and even longer time horizons) and BSPs take the commitment to reserve these capacities from their portfolio. This mechanism makes sure that there are sufficient flexibility resources to maintain an adequate safety margin. It implies that BSPs cannot apply these capacities to other markets. Reserved capacity is expected to be available in real-time and has to bid in real-time balancing energy markets because otherwise BRPs may need to pay the fine.

2. Balancing energy market: this refers to real-time (following last intraday gate closure for the relevant trading period) energy markets that allow TSOs to balances the system by accepting balancing energy bids and balancing reserve contracts. The price is determined in real-time and the price of bids from balancing reserve contracts is not predetermined.

Balancing the reserve market provides a capacity remuneration that consists of all potential costs that occur for keeping the services available to the grid. The balancing energy market also provides an energy-based remuneration. For positive services, the service provider is directly remunerated from TSOs. For negative services, the price can be negative as the service provider also gains compensation from the spot price (Ocker, 2017).

Figure 2: Example of negative services (aFRR) pricing (Austria, 01.05.2018)

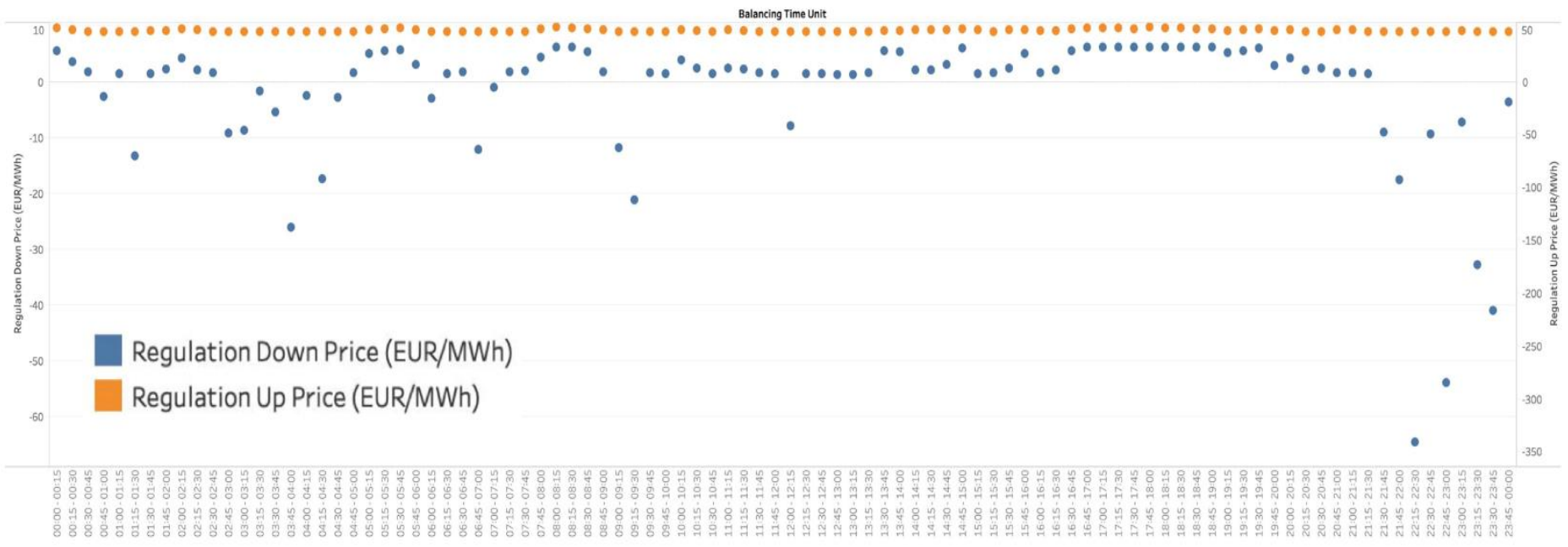

Source: ENTSO-E Transparency Platform

\section{The evolution of decentralized flexibility}

Decentralized flexibility can become a valuable resource for system balancing and grid management. Although, currently, there is a limited business case it them to evolve, many technological improvements and emergence of new market actors are offering the opportunity for decentralized flexibility to participate in the markets.

\subsection{Decentralized flexibility for demand-side management}

The DFS considered in this paper are primarily load resources. They are recognized within the electricity system as demand response (DR) or demand-side management (DSM). This kind of program has existed within the electricity system for several decades. It is one of the oldest tools to help system operators maintain system balance. Typically, system operators use manual load shedding or rolling blackout to secure the grid system during emergencies. A broader definition of DR is a program established to incentivize changes in electricity consumption patterns. It considers the intentional changes of electric usage from their normal load patterns and acts as some form of flexibility within the 

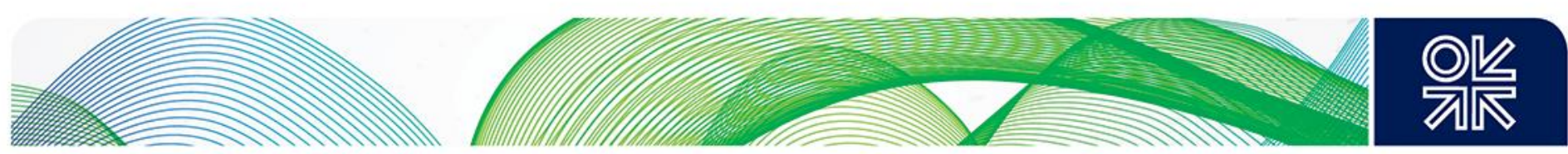

electricity market and grid management (EnerNOC, 2011; Meeus \& Nouicer, 2018; Zancanella \& Bertoldi, 2017). In the conventional supply-centric electricity system, demand is matched passively by supply, so demand response is mainly used for planned reductions in load (IEA, 2017a). In the context of high-variability VRE generation, both upward and downward response are required.

DSM was neglected in policy facilitation in the first decades of this century (Richter \& Pollitt, 2016; Zancanella \& Bertoldi, 2017). In recent years, the policy support has been growing due to the prospect of increasing system operation and investment efficiency with the introduction of DSM (Bahrami et al., 2018). At the European Union level, it includes the Third Energy Package of 2009 and Energy Efficiency Directive of 2012, which contain the promotion of smart meters and allow for the introduction of timebased prices (Chase et al., 2017). Lately, the European Commission's Clean Energy Package also provides measures to promote better integration of electricity from renewable sources and support power evolution towards a more intermittent, non-synchronous generation fleet (Meeus \& Nouicer, 2018; Minniti et al., 2018; Poncela, 2018). Initial progress has been made in encouraging industrialscale customers to offer energy services. Member states (MSs) such as France, Finland and Belgium are at the forefront of the development (ENTSO-E, 2019). Although an increasing number of markets are open to DSM, the reporting of exact volumes is low.

\section{Implicit DSM vs. explicit DSM}

There are in general two types of mechanism that enable DSM (IRENA, IEA \& REN21, 2018; Meeus \& Nouicer, 2018; Zancanella \& Bertoldi, 2017):

- Explicit DSM: It manages bulk load shifting through corresponding market mechanisms. Demand capacity is sold by consumers, directly or through aggregators, to the market or the grid operator. The demand thus competes directly with supply in different market segments. Consumers receive direct payments to change their consumption upon request.

- Implicit DSM: It provides incentives that allow consumers to respond to price signals. Consumers have exposed means such as time-varying tariffs which are specified by their retailers and reflect the real or expected cost of electricity provision. There is no direct reward to consumers other than reducing their electricity bills.

Implicit DSM and explicit DSM are two different business models which require different skills sets and different market designs. People tend to mix up the two during the public discussion. Although DFS can participate in the electricity system through both mechanisms, the explicit DSM is preferred, with sound reasons which are explained below.

Implicit DSM has been well elaborated by plenty of publications (IRENA, IEA \& REN21, 2018; Zancanella \& Bertoldi, 2017; CEPA, 2014). It emphasizes technologies and pricing mechanisms through means like in-house display, time-of-use tariffs, critical-peak-pricing and utility load control to communicate scarcity in the energy supply and stress on networks (Eid et al., 2016). Tariffs that consider time-of-use provide the opportunity for consumers to benefit from wholesale price fluctuations (USEF, 2015). There are also programs that use 'information only' as a signal for implicit DSM to advocate renewable electricity consumption; in this case, the information can be a low wholesale price as renewable energies tend to bid lower price as they have low marginal costs (Chase et al., 2017). Such arrangements are mature and follow the conventional utility-driven model. The implicit DSM process is simpler, as it does not require extra information on baseline consumption. It demands simpler and cheaper infrastructure and users are left with more freedom to respond (Eid et al., 2016). It has great potential for electric vehicle $(E V)$ charging time management and more effective consumer energy optimization with more granular time-based tariff design (IEA, 2018a; NVE, 2016; Wargers et al., 2018).

However, implicit DSM is less effective from the electricity system perspective. With implicit DSM, the real benefit of active participation become ambiguous for the customer as the economic payback is largely shaded by the compound electricity bill. It was found that consumers cannot respond effectively to the price change and incentive signals (Ghazvini et al., 2017). The primary design of the billing 

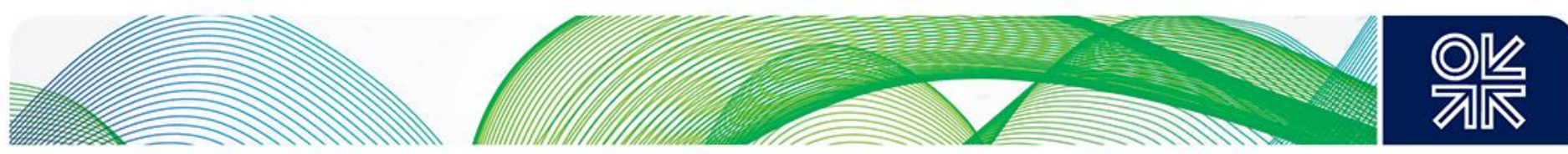

process is cost recovery for the electricity value chain in an acceptable way, instead of providing the incentive to the consumer for efficient consumption behaviour (Healy \& MacGill, 2012; Schittekatte \& Meeus, 2018a). Nonetheless, the electricity bill is a combination of electricity wholesale price, regulated transmission and distribution charges, and retail costs, plus value-added tax, levies and any other surcharges ${ }^{19}$ (ACER \& CEER, 2017). Electricity prices vary dramatically between moments in time, between location, and according to lead-time between contract and delivery (Hirth et al., 2016). Tariffs and retail prices for the most part approximate to an averaging of the costs of supplying electricity. With current electricity billing methodologies, there is very limited ability to differentiate incremental costs and become system-cost reflective (Rhys, 2016; CEPA, 2014; Schittekatte \& Meeus, 2018b; Carmichael et al., 2018). Also, asking consumers to adapt their daily routine to fit with the electricity program and understand updated existing technologies would be complicated and have a considerable knowledge gap (Paetz et al., 2012).

The value of DSM participation will be better realized through explicit DSM. Explicit DSM programs allow flexibility resources to be traded through the electricity market (ENTSO-E, 2019). In particular, only explicit DSM can provide network services to enforce system reliability and engage balancing markets at a shorter timescale (CEPA, 2014).

Current explicit DSM participants are mostly large-scale electricity consumers in the industrial or services sectors, as these sectors have the greatest practical commercial capability to manage shortterm demand and business models do work with them, as any market transaction will only happen if the cost of carrying out the transaction is less than the expected benefit. Due to lower transaction costs,$^{20}$ there is still a consensus that flexibility would be sourced from large-and medium-scale sources before tapping flexibility from small-scale consumers (Verhaegen \& Dierckxsens, 2017). The DSM activity from individual households is still largely limited and many business cases are still unfeasible due to lack of economic incentives, technological complexity and political barriers (Verhaegen \& Dierckxsens, 2016). Traditionally, the cost and effort involved in communicating and equipping residential customers are comparably high and the foreseeable benefits are negligible (IEA, 2017; Hesser \& Succar, 2012). Meanwhile, there are often fixed transaction costs associated with any market participation, such as registering costs and market-required insurance. For small-scale capacity participants, this means high transaction costs per unit of output (Burger et al., 2016). With digitalization, even though the fixed cost of market participation is barely decreased, the development of ICT and growing of its applications do significantly decrease the cost of pooling all distributed demand-side capacities, which provides the potential to allow decentralized flexibility to become involved.

However, it should be borne in mind that the current wide rolling out of smart meters has more direct impacts on the development of implicit DSM than explicit DSM. The finer granularity and the nearly realtime communication would enable more complex implicit DSM tariff designs and improved load forecast. On the other hand, the wide rolling out of smart meters could enhance the baseline design for explicit DSM. Nevertheless, explicit DSM needs greater functionalities of metering infrastructure and ICT components. It requires dedicated ICT infrastructure, and the current design and installation of infrastructures are locked in with contracted parties with limited interoperability (CEPA, 2014).

\subsection{The market design for decentralized flexibility preservation}

Within Europe, regulating authorities have committed to a market-based approach and facilitate a competitive electricity market to provide effective price signals to electricity dispatch (Papavasiliou, 2018; Newbery et al., 2017). The market design needs to provide neutral incentives and allow all kinds of technologies to develop in parallel. Regulatory authorities should commit to a market-based approach

\footnotetext{
${ }^{19}$ In 2016, in EU capitals and Oslo, the final electricity bill consisted of energy costs (35\%), taxes and levies (38\%), network chargers $(27 \%)$.

20 Transaction costs can be categorized into three broad categories: research and information costs, bargaining costs and enforcement costs.
} 

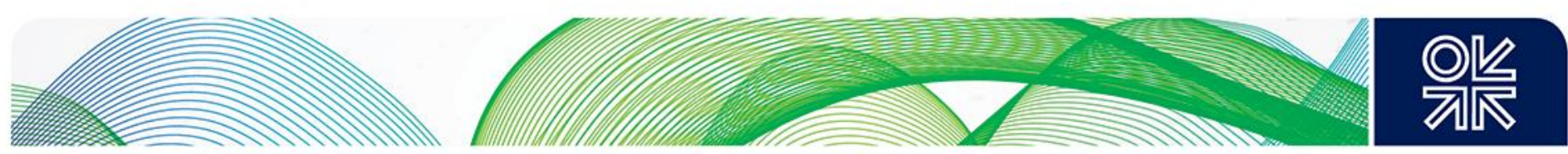

and facilitate a competitive electricity market (Meeus \& Nouicer, 2018; Zancanella \& Bertoldi, 2017). All available resources, including DFS, should be allowed to participate in potential electricity markets. As only explicit DSM can allow decentralized flexibility to provide different grid services and be traded through the electricity market, the following discussion on market design for decentralized flexibility only concerns explicit DSM.

The market design to enable decentralized flexibility primarily means allowing it to remunerate from appropriate market design and dispatch with appropriate signals. Currently, there are no consented models for the market arrangement to enable decentralized flexibility. However, many trials and pilot projects are exploring potential solutions (Migliavacca et al., 2017; Marroquin et al., 2018; Gangale et al., 2017). However, the evolving of feasible solutions is mostly dependent on existing market arrangements and the available DFS.

With appropriate enabling infrastructures, redefined products and market prerequisites, DFS can actively participate in existing wholesale markets, capacity markets and balancing markets, (SEDC, 2017). Meanwhile, with the increasingly complex distribution grid environment, DFS can participate in the potential emerging markets at the distribution level to facilitate active distribution network management (Eid et al., 2016; Schittekatte \& Meeus, 2019). For example, the experimental EPEX SPOT local flexibility market platform, and GOPACS launched by Dutch grid operators, are pooling platforms that allow system operators to procure flexibility with locational information dedicated to congestion management (Hans \& Reek, 2018; TenneT, 2019). However, there is, as yet, no existing regional market ${ }^{21}$ beyond pilot projects (Gerard et al., 2018). There are also many potentials for new products design with aggregated DFS. For example, to address concerns about losing reactive power and increasing voltage control requirement from VRE generation, new products can be designed accordingly at different market levels (Merino et al., 2016). There are ongoing pilots, such as the Power Potential project in the South East region of Great Britain, which allows procurement of reactive power with a local market.22

\section{Aggregation and aggregator: Role and regulation}

Aggregation plays a central role in enabling decentralized flexibility. It represented the grouping of distinct agents in a power system to act as a single entity and engage in power markets. An individual DFS does not provide sufficient reliable electric flexibility (Zancanella \& Bertoldi, 2017). Thus, it is necessary to simultaneously bundle DFS to provide tradeable amounts of flexibility (Eid et al., 2016). An aggregator is a market agent who conducts aggregation and acts as an intermediary between the market and small participants. It acts as a translator who translates decentralized data into quantity bids and enhances the effectiveness of explicit DSM programs (Zancanella \& Bertoldi, 2017; Burger et al., 2016; Glachant \& Rossetto, 2018). An argument some people use is that under certain circumstances, individuals can eliminate intermediaries and participate in market trading on their own. However, there are prohibitive technical and administrative burdens for individual active consumers to participate in market-based dispatch. The role of aggregation and aggregator thus are necessary to facilitate active consumers for efficient market operation of decentralized flexibility.

The most successful innovation enabled by aggregation based on new technologies so far is the Virtual Power Plant (VPP). This involves bundling household batteries and maybe other small-scale generation resources into one portfolio to bid in a different market at a strategic time. The accounted capacity of VPP in Europe was around 18 GW in 2017 (IEA, 2018a). An excellent example of decentralized flexibility is the household battery provider Sonnen, which has recently been approved to participate in the balancing market of TenneT in Germany and to provide FCR by aggregating decentralized power generation and storage from households (Eckert, 2018). To validate the functionality and

\footnotetext{
${ }^{21}$ Market at distribution, regional market and local market level have a relatively similar meaning, which is differentiated from the traditional wholesale market.

${ }_{22}$ Power Potential project: https://www.nationalgrideso.com/innovation/projects/power-potential
} 

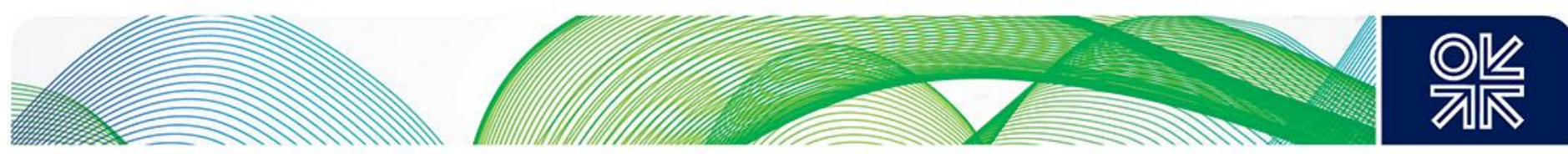

responsiveness, Sonnen's $1 \mathrm{MW}$ virtual blocks were put on the grid, discharging and recharging a full $1 \mathrm{MW}$ of power in under 30 seconds (Field, 2018). Similar energy management technology is held by many companies like Limejump, Tesla, etc., and the application is flourishing in many countries.

Aggregators maintain the contractual relationship with flexibility assets owners (including active consumers and larger-scale industrial or business consumers) and offer value to BRPs, energy suppliers, DSOs and TSOs to optimize their portfolio (USEF, 2015; Verhaegen \& Dierckxsens, 2016). They need to negotiate agreements with active consumers to aggregate their load. During this process, they can tackle transaction barriers including incomplete information, irrational price responsivity and the lack of knowledge and experience of consumers to identify their flexibility potential (IEA, 2018b). They also provide new services and active interactions with system operators. Additionally, they can hedge the uncertainties of non-delivery from a single active consumer so that the quality of service can be guaranteed (USEF, 2015).

Although aggregators are recognized by their role of aggregating demand-side flexibility, the practical role of aggregators is still defined by regulators according to the activities they can perform (Burger et al., 2016; Gerard et al., 2018). In many MSs, the role of aggregators is not clearly defined and some MSs still forbid this role (Zancanella \& Bertoldi, 2017). Two types of aggregator models have emerged in Europe. One is known as the independent aggregator, where the aggregator serves as a provider of flexibility provision. The other model is conventional energy retailers who developed the aggregation business to complement their existing supply business (Verhaegen \& Dierckxsens, 2016). Independent aggregators provide more potential to enhance market competition. According to ENTSO-E (2019), there are currently 41 independent aggregators, and at least 22 energy retailers have aggregation businesses. The initial business cases are still focusing on large-scale industrial and commercial customers.

The regulation of aggregators needs to balance the benefits of the competition, economies of scale and economies of scope (Burger et al., 2016). Competition can encourage innovation but also diminishes the economies of scale. Economies of scope is another factor that needs to be considered during regulation. For an aggregator, the fixed costs would mostly be algorithms and software costs. During the engagement with customers, there are inherent acquisition costs and end-user hardware costs as variable costs (Verhaegen \& Dierckxsens, 2016). It would be more efficient for a single aggregator to bundle all required services for a single customer, rather than multiple aggregators each procuring or delivering a single service. In particular, different services could share common devices and communication protocols, and the bundled services are likely to go beyond the electricity sector for more innovative solutions (USEF, 2015; Burger et al., 2016).

Another vital issue that needs to be settled for decentralized flexibility to evolve is the financial settlement between aggregator and supplier (BRP). Currently it might be the single most crucial factor shaping the business model of decentralized flexibility. In member states other than France and Switzerland, there is no such framework to settle the dispute between aggregators and BRPs (Verhaegen \& Dierckxsens, 2016; Minniti et al., 2018; DNV GL, 2017a). The major difficulty for such settlement is to design a baseline for DFS that can well reflect the caused imbalance on BRPs profile by any service activation of DFS.

The baseline is essential to identify the value of explicit DSM. It is necessary to calculate the imbalance for settlement and assess the quality of activation. Thus, a baseline must be predefined, standardized and agreed by all stakeholders as an estimate load profile that would be consumed by a customer in the absence of a DSM event (USEF, 2015; EnerNOC, 2011). The real-time metering data from the period of the event is compared with the baseline to determine the magnitude of the electricity resources (EnerNOC, 2011, Holmberg et al., 2013). With the identified quantity of shifting demand from participants, the financial payment or penalties can be allocated correspondingly (Glodberg \& Agnew, 2013). The design of baseline for larger-scale industries and businesses would be much easier than DFS as there is more scale effect with one single improvement of infrastructure. However, currently, 

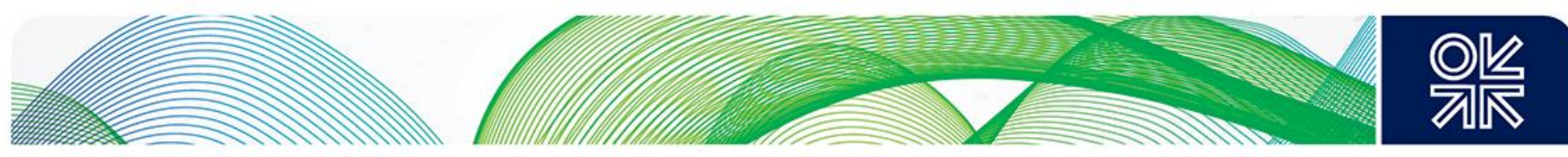

there is limited infrastructure and availability of data to support a baseline methodology for DFS, especially for an individual household. For example, if the smart meter only measures the power level (kW) every five minutes, any power shift within that five-minute interval will be ignored but the accumulate energy ( $\mathrm{kWh}$ ) will have an impact on the overall energy consumption in that five minutes and count as imbalance. In the day-ahead market, BRPs submit their forecasted load profile (kWh) and are responsible for the imbalance of their profile in real-time. If an aggregator contracts the end-users within the profile of a BRP and activates the flexibility service in real-time, then the BRP would face an energy ( $\mathrm{kWh}$ ) imbalance caused by the activation. Fair compensation to the BRP needs to be arranged. However, it is a challenge to ensure that such compensation reflects the loss, as the imbalance cost calculation requires an advanced metering system to measure the energy imbalance (kWh) and the wide rolling out of smart-meters that are capable of measuring energy imbalance at really short timescale is missing. There are considerable costs to tackling this problem and the cost-benefit analysis outcome would vary case by case.

Currently, in many MSs that allow aggregation, aggregators need to negotiate a bilateral agreement with BRPs to pay an 'agreeable' amount of money to cover the BRPs' sourcing costs (Zancanella \& Bertoldi, 2017; Verhaegen \& Dierckxsens, 2016). In this circumstance, energy retailers (BRPs) plus aggregation businesses could become the prevailing model. Many independent aggregators would transform into a model combining both retailer and aggregator roles, as once an aggregator become a BRP, it could then avoid the negotiation process and ignore the complexity of settling the baseline. However, in doing this, the entry barriers for aggregation businesses would significantly increase (Verhaegen \& Dierckxsens, 2017). At the same time, this also partially explains why FCR and other quick-frequency response products have been the first among balancing products to become feasible to provide by DFS. Without an appropriate baseline to calculate the energy component, the capacitybased remuneration is favoured over energy-based remuneration. ${ }^{23}$ Among balancing services, FCR has the lowest energy component and relatively high capacity remuneration for aggregators. Also, it is more acceptable to BRPs because FCR only causes marginal energy imbalance in their profile (Elia, 2017; Verhaegen \& Dierckxsens, 2017). At the moment, only the framework from Switzerland allows independent aggregators to have direct contracts with end-users without explicit permission from BRPs: after the activation of flexibility services, the Swiss TSO corrects the position of each BRP considering all the flexibility activation that has modified its position; the BRP then receives compensation based on quarter-hourly day-ahead price (Minniti et al., 2018; Verhaegen \& Dierckxsens, 2017). This model allows system operators to correct the imbalance position centrally for BRPs and letting aggregators contract freely with active consumers would be preferred. Meanwhile, as the EU is pursuing common European cross-border balancing markets, the framework to coordinate BRPs and aggregators is best coordinated at EU level to guarantee a fair competition environment for cross-border trading.

\section{The required market design: Market access}

One primary concern for decentralized flexibility to participate in existing markets and emerging markets is market accessibility.

There are three perspectives related to market access limitation: product specifications, market entry prequalification and trading arrangements (CE Delf \& Microeconomix, 2016; Schittekatte \& Meeus, 2018a). Product specifications include minimum bid requirements on parameters such as volume, notification time, availability, contract period, duration of one action and ramp rates (CE Delf \& Microeconomix, 2016, van der Veen et al., 2016). The specification is the core to define an electricity product. Market entry prequalification concerns include standard license conditions, compliance with regulatory frameworks and industry codes, and respecting the corresponding balancing and settlement

\footnotetext{
${ }^{23}$ If the balancing service provider is also the BRP itself, the energy component can be indirectly compensated via an imbalance mechanism, as the activation of such decentralized flexibility is likely to provide a positive imbalance price (Elia, 2017).
} 

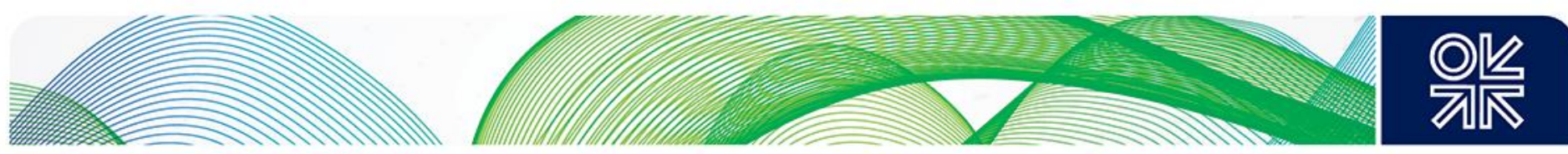

code. Trading arrangements concern technical and operational prerequisites, including compliance with information, measurement, verification and communication protocols.

The value of flexibility can only be appreciated when it can be applied in a designed market product (Hans \& Reek, 2018). All market agents that want to participate in the market have to adopt the same practices and business processes, which are specified in the Network Codes ${ }^{24}$ (ENTSO-E, 2018). Meanwhile, there is a prerequisite for resources and market agents to make sure that the DSM can be delivered in a reliable manner (Zancanella \& Bertoldi, 2017). The preconditions of bidding into a balancing market are even stricter (Scherer et al., 2015). Sometimes, these preconditions act as discrimination against aggregated resources and DFS (Borne et al., 2018; Schittekatte \& Meeus, 2018a; Paterakis et al., 2017).

Considering the aggregated DFS, the concerns of minimum bid volume requirements, symmetric bid requirements, and the duration of one action and contract period have been well discussed and are organized in Table 4 (Burger et al., 2016; Schittekatte \& Meeus, 2018a; CE Delf \& Microeconomix, 2016). There have been many positive changes to facilitate the market access of DFS. The recent trend shows the removal of entry barriers for DFS to participate in the electricity markets, although some barriers still exist (smartEn, 2018a; Eid et al, 2016).

Table 4: Identified market access barriers

\begin{tabular}{|c|l|}
\hline Type of issues & \multicolumn{1}{c|}{ Descriptions } \\
\hline $\begin{array}{c}\text { Symmetric bid } \\
\text { requirement }\end{array}$ & $\begin{array}{l}\text { Symmetrical offering requirement asks a single unit to provide the same } \\
\text { level of downward regulation and upward regulation simultaneously, } \\
\text { which is technically impossible for many DFS. For aggregators, it means } \\
\text { that they must aggregate the same amount of downward and upward } \\
\text { reserves concurrently, which can be difficult sometimes. }\end{array}$ \\
\hline $\begin{array}{c}\text { Minimum bid size } \\
\text { Time factors (duration } \\
\text { for availability, } \\
\text { contract period, } \\
\text { contract time and } \\
\text { frequency of auction) }\end{array}$ & $\begin{array}{l}\text { A lower minimum bid size lowers the entry barriers for new players, } \\
\text { especially in the balancing market. }\end{array}$ \\
\hline $\begin{array}{c}\text { the longer the duration of availability, the higher the opportunity cost for } \\
\text { their behaviours, thus the more restrictive for resource preservation from } \\
\text { aggregated DFS; contract time indicates how long the procurement of } \\
\text { reserves is made ahead of delivery. If the procurement is one year before } \\
\text { delivery, the aggregators have to forecast their available load, which } \\
\text { brings extra burden and relative costs; more frequent auctions with } \\
\text { shorter contract duration would allow less burden to forecast the available } \\
\text { load and reduce the corresponding forecast costs. }\end{array}$ \\
\hline
\end{tabular}

Sources: Schittekatte \& Meeus, 2018a; Zancanella \& Bertoldi, 2017; Borne et al., 2018.

A new set of market access requirements needs to take into account system reliability requirements and the different characteristics of DFS to enable technology-neutral market participation (Zancanella \& Bertoldi, 2017). Nonetheless, some balancing market products in MSs are still contracted through bilateral contracts or administrative rules without transparent pricing and procurement processes. Overall, the progress is oriented in the market open direction following the European agenda (Anaya \& Pollitt, 2018; Borne et al., 2018). Moreover, the costs of system operators and market operators to open

\footnotetext{
${ }^{24}$ Network Code is the technical rulebook that defines common market behaviours.

25 The minimum bid size for the day-ahead market and intraday market are already low enough at the current stage. The minimum bid volumes for day-ahead and intraday market in countries like Germany and France are only 0.1 MW (Agora, 2016).
} 

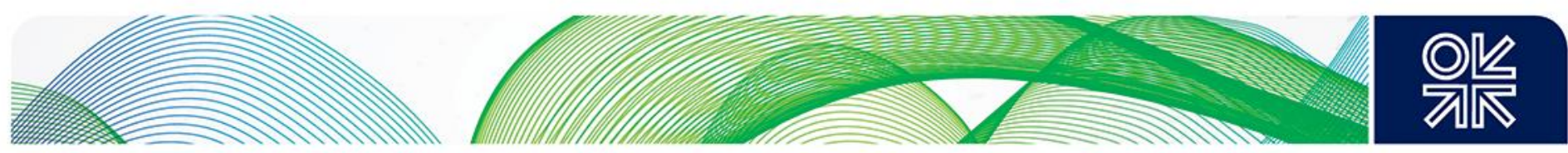

the market to aggregated DFS should be identified. The prequalification and ex-post measurement and verification would add extra complexity to system operators. The reduced minimum bids, redefinition of products, frequent auctions and asymmetrical bids would increase the number of transactions and associated management costs. System operators need a learning process to manage such practices of procurement services from DFS and conduct prequalification tests. Principally, aggregators have the responsibility to demonstrate to system and market operators their ability to deliver corresponding services (Borne et al., 2018).

\section{The required market design: Remuneration mechanisms}

Appropriate remuneration schemes and pricing mechanisms for aggregated DFS is the core to allow decentralized flexibility to evolve. An effective pricing mechanism can provide correct incentives and guarantee a cost-reflective market environment (Papavasiliou, 2018).

For existing electricity markets and potential emerging markets, the remuneration schemes need to provide an appropriate price signal to facilitate effective flexibility dispatch and unlock potential DFS.

Currently, the balancing service market remunerates the required services based on a wide range of pricing mechanisms such as mandatory provision, fixed prices, bilateral contracts and auctions (Pollitt \& Chyong, 2018). Among these mechanisms, only auction is market-based. It is likely that in the future auctions will be used for most services dedicated to decentralized flexibility. In this way, auction rules have a direct impact on the bidding behaviour and outcomes of the service suppliers (Ocker et al., 2016; Keay \& Robinson, 2019).

However, a suitable pricing model for DFS is missing at the distribution level. Centralized generation use marginal cost as the benchmark to justify whether the market can provide effective remuneration. Aggregators act on behalf decentralized flexibility assets owners to participate in the market. The value of the flexibility from individual active consumers cannot be quantified effectively, thus, cannot be remunerated correspondingly. There are also no clear principles for market remuneration re-allocation between aggregator and active consumer. Thus, in the emerging business model, aggregators play an active role in offering an appealing value to active customers to provide DFS at the distribution level.

Some stakeholders argue that only value-reflecting marginal pricing mechanisms can provide efficient remuneration for DFS (Good et al., 2017; smartEn, 2018a; Accenture, 2018). Thus, a nodal pricing model would be necessary to reflect the LMP ${ }^{26}$ of any DFS. However, currently there are no large-scale nodal pricing mechanisms that have been applied at the wholesale level within Europe. It might be difficult to pursue nodal pricing for the distribution level with political enforcement (Schittekatte \& Meeus, 2018a). The distribution level nodal pricing mechanism would evolve in a decentralized manner as a dedicated regional project requirement. For example, the Cornwall Local Energy Market trial in South West England, UK, which involves 100 plus homes, has developed its local nodal model for the regional market operation. ${ }^{27}$

\section{The way forward for decentralized flexibility}

Decentralized flexibility as one of the resources for electricity flexibility is only a recent development. The field is young; the way forward has great possibilities but also uncertainty. Many factors have the potential to provide encouragement or to block future development. In this section, the complete market environment for future decentralized flexibility development is discussed. The debate regarding a common framework versus a customized framework for decentralized flexibility preservation is considered, and some exciting emerging market design innovations are discussed.

\footnotetext{
${ }^{26}$ For DSM, it would be LMP-G, with G standing for the retail price according to customers' retail contract for electricity (CEPA, 2014)

${ }^{27}$ Cornwall Local Energy Market: https://www.centrica.com/innovation/cornwall-local-energy-market
} 

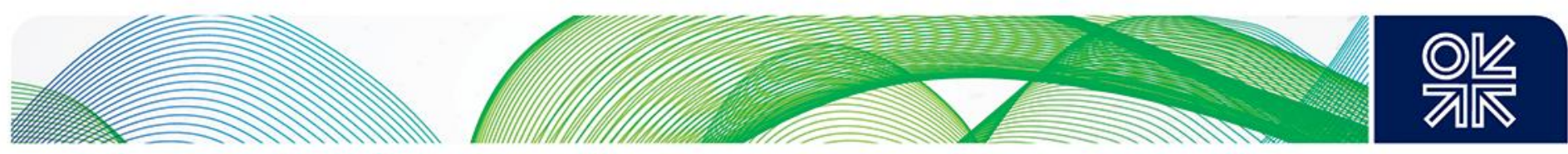

\section{The uncertain market environment}

As one of several potential sources of electricity flexibility, decentralized flexibility has to compete with other flexibility resources such as generation, interconnections, grid-level storage and demand response from industrial sectors (de Jong et al., 2017; Carmichael et al., 2018). The monetization of DSM depends on many factors other than regulations. The economic value of DFS depends upon the specific demand at different timescales from the local electricity market. More than that, at the regional level, the value of DSM will be higher in the systems that need considerable reinforcement than the systems which have plenty of spare grid capacity (Eid et al., 2016). The business case is determined by the cost of operating the program and potential generated revenues (DNV GL, 2017).

The broader electricity market design and related policies will also significantly influence the economic incentive of DFS. The European strategies to guarantee sufficient electricity flexibility in the member states (MSs) follow two major paths (Redl, 2018): cross-border integration of power systems and flexible sets of power markets. Cross-border trading allows the surplus in one balance area can be exported to neighbouring areas. Thus, cross-border integration would lower electricity prices for importing countries (IEA, 2018; Redl, 2018). Moreover, many MSs have decided to implement different designs of capacity mechanisms. In February 2018, Belgium, France, Germany, Greece, Italy and Poland were approved by the European Commission to deploy their capacity mechanisms (Meeus \& Nouicer, 2018). Such mechanisms serve as an instrument that provides additional revenues to the required electricity resources (IRENA, IEA\&REN21, 2018). In general, the better the emergence of scarcity price and high price volatility, the more incentives there will be for market agents to invest to enable DFS (EC, 2015). Inevitably, the implementation of capacity mechanisms compromises the emergence of scarcity pricing and incentives to use decentralized flexibility (Hogan, 2015). Nevertheless, decentralized flexibility can still be dedicatedly promoted with dedicated market design, for example, a specific auction product that only allows aggregated DFS to participate, or capacity reserve that incorporates DFS (BMWi, 2015). Meanwhile, relatively high carbon emission costs could help DFS to compete over conventional flexibility resources such as gas and coal power plants. After reforms, the price of EU ETS reached €27 in early 2019. Further increase the effectiveness of the EU emissions trading system (ETS) has become the focus for the period after 2020 (CAT, 2018).

\section{Common vs. customized framework for decentralized flexibility preservation}

The use of DFS requires considerable capabilities of different stakeholders within the electricity system. There is a debate about whether a common framework for decentralized flexibility preservation is needed. Currently, there are no normalized frameworks and agendas to encourage the involvement of active consumers (Merino et al., 2016). It is argued that a common framework, such as normalized contracts or standardized prequalification, measurement and verification guidelines, could help to quickly expand the existing experience, facilitate cross-border trading and significantly merge knowledge gaps (Zancanella \& Bertoldi, 2017; USEF, 2015). However, the gradually emerging consensus in the sector suggests that customized bilateral contracts and technology tailored prequalification are preferred at the current development stage (Verhaegen \& Dierckxsens, 2017).

The European energy mix is characterized by diversity at the national level in terms of availability of energy resource, and at the regional level in terms of infrastructure maturity and dynamics, such EV adaptation rate and level of VREs (EY, 2019; ENTSO-E, 2019). Each MS puts different weights to decarbonization objectives and MSs have diverse access to energy supply resources. Such a situation implies that different MSs will take different paths and divergent market arrangement to achieve longterm development targets (Pollitt \& Chyong, 2018; Eurelectric, 2018). The demand for flexibility services has largely relied on regional circumstance and is far from one-size-fits-all. Consequently, the pace of development and utilization of DFS are quite diverse among MSs and a common framework could end up becoming too complex to employ.

On the other hand, there are various technical capabilities and economic characteristics of DFS that are unique. For example, the German aggregator Next Kraftwerke has initiated a unique project to 

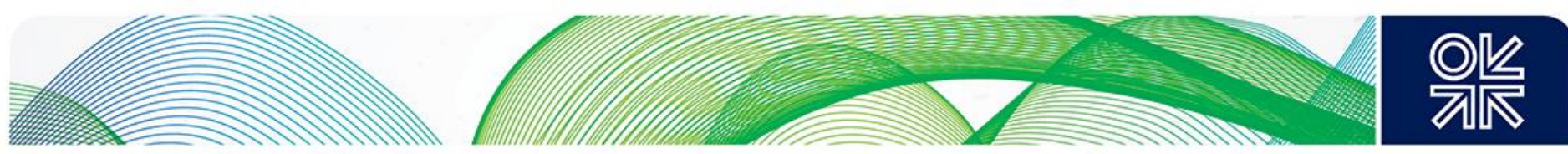

control battery reserves in electric automated guided heavy goods vehicles to provide FCR. With this project, Next Kraftwerke is developing the concepts for the fleet's prequalification. ${ }^{28}$ Therefore, it is more pragmatic to use customized prequalification and adoption frameworks and allow for different innovative applications to emerge for the current development phase.

Most importantly, the evolving of the feasible market model and exact design for decentralized flexibility are largely dependent on existing market arrangements, regional resource availability and regional flexibility requirements. Consequently, the pace of development and utilization of DFS are quite diverse among MSs. The integration of decentralized flexibility into electricity market design would be more likely to be developed in a decentralized manner somewhere there is a significant demand for electricity flexibility but where there is a limited centralized supply (Ocker et al., 2016).

\section{Emerging innovative market designs}

There is a learning process for system operators to manage the decentralized flexibility. There have been some innovative market arrangements that are different from conventional market arrangement which may have a significant impact on future development. However, further research is still required to explore the reliability of these innovations and their trustworthiness.

To begin with, as previously discussed, the emergence of a nodal pricing model in a decentralized manner could provide a further possibility for electricity market design. With nodal pricing to reflect the LMP of all DFS, a value-reflective price can be set to encourage more efficient electricity consumption and transparent benefit sharing between aggregators and active consumers.

Moreover, there is significant concern that the lack of liquidity at the distribution level market may cause the abuse of local market power and inefficient price discovery (Hadush \& Meeus, 2017; CE Delft \& Microeconomix, 2016; MacDonald, 2013). As a way to counter the lack of liquidity, some trials and pilot projects are enabling advanced energy contracts. This means that there will be more information collected during the bidding process and the bids can be called if the predefined conditions (justified during the bidding process) are satisfied in real-time (DNV GL, 2018). Thus, there will be more available bids for regional markets, increasing the liquidity to counter market abuse.

Furthermore, existing aggregators are trying to maximize their profitability through cross-market optimization. For example, single or pooling assets can bid in different time-sequential and parallel markets to maximize the benefit of assets. Relative stakeholders want to be allowed to submit multiple bids simultaneously to different market products to achieve maximized realization of their flexibility assets (smartEn, 2018a). As if the bid is not activated in one service or standardized product and can directly qualified to be activated in the next one sequentially.

All these innovative approaches are emerging from the market and may play a significant role in future market design. Further research is necessary to gain more understanding on these approaches.

\section{Conclusions}

This paper has focused on the interaction between decentralized flexibility and electricity market design. Flexibility from decentralized resources is a young and complex domain. To embrace the widespread decentralized components and realize the decarbonization targets, the power system requires a reexamination of the existing operational model. The research and understanding are far from sufficient. Even though many discussions in the paper also apply to decentralized generation resources, the article narrowed the study down to decentralized load resources for demand-side management. The conclusions drawn from this paper include:

${ }^{28}$ Next Kraftwerke: https://www.next-kraftwerke.com/news/fresh-ideas-for-electrifying-port-logistics 

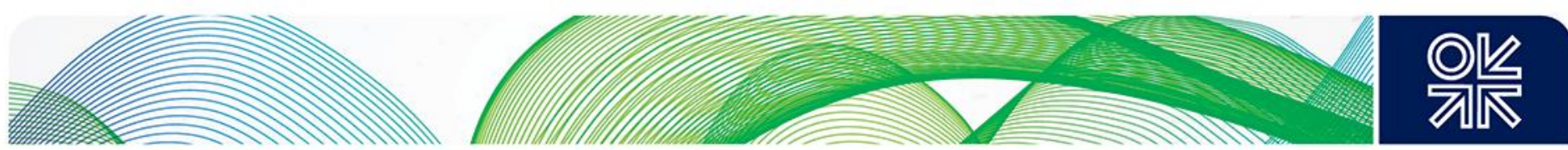

Being able to use decentralized flexibility has strategic importance as there will be no electrical flexibility from conventional power plants in a fully decarbonized electricity system. To enable the use of decentralized flexibility requires a learning process from system operators.

Both implicit and explicit DSM are essential mechanisms to enable DSM. However, explicit DSM can better realize the value for decentralized flexibility as only it can provide network services to enforce system reliability and engage balancing markets on a shorter timescale.

The market design to enable decentralized flexibility primarily means allowing it to remunerate from appropriate market design and be able to dispatch with proper signals. The opening up of the market to DFS brings extra costs to market and system management that need to be acknowledged by corresponding parties. With adequate enabling infrastructures, DFS can participate in existing markets, emerging markets at the distribution level and other potential new products it fits. Moreover, a suitable pricing model for DFS there is missing at the distribution level. Currently, the auction is primarily used for pilot applications but is not necessarily the optimal method.

Aggregation and aggregator are necessary as digitalization barely reduces the transaction costs for market participation, but significantly decrease the cost of pooling all the distributed demand-side capacities. Aggregators have to help active consumers to overcome the prohibitive technical and administrative burdens to participate in the market-based dispatch. They have to actively interact with system operators and market operators to demonstrate their ability to deliver corresponding services. The existing regulation on aggregators has been largely shaping the emerging business application. The precondition of a bilateral agreement between BRP and aggregator has increased the entry barrier for the aggregator.

DFS encompass different load sources and a wider variety of technical and economic characteristics. The emergence of business applications and monetization of DFS depend on many factors, such as broader electricity market design and energy policy, regional resource availability and penetration level of VRE. Consequently, the pace of development and utilization of decentralized flexibility sources (DFS) will be diverse among the European member states. The integration of decentralized flexibility into the electricity market is more likely to be developed in a decentralized manner that starts from an area that requires electricity flexibility but lacks centralized supply. 

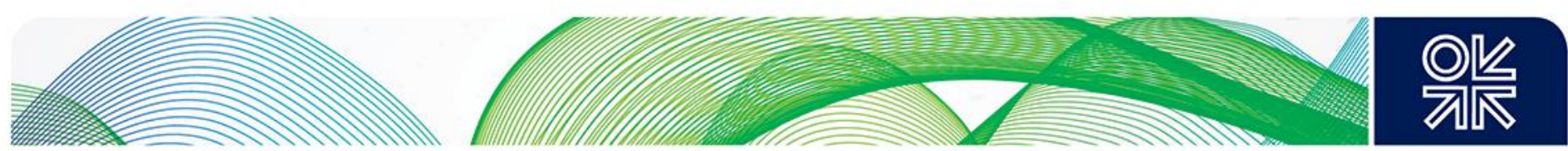

\section{Bibliography}

Accenture (2018). 'Flex and Balances: Unlocking Value from Demand-side Flexibility in the European Power System'.

ACER and CEER (2016). 'Annual Report on the Results of Monitoring the Internal Electricity and Gas Markets in 2015', Agency for the Cooperation of Energy Regulators.

ACER and CEER, (2017). 'Annual Report on the Results of Monitoring the Internal Electricity and Gas Markets in 2016', Agency for the Cooperation of Energy Regulators.

Agora (2017), 'Energiewende 2030: The Big Picture - Megatrends, Ziele, Strategien und eine 10Punkte-Agenda für diie zweite Phase der Energiewende'.

Anaya, K.L., and Pollitt, M. G. (2018). 'Reactive Power Procurement: Lessons from Three Leading Countries', Energy Policy Research Group.

Bahrami, S., Amini, M. H., Shafie-khah, M., and Catalao, J. P. (2018). 'A decentralized electricity market scheme enabling demand response deployment', IEEE Transactions on Power Systems, 33(4), pp. $4218-4227$.

Borne, O., Korte, K., Perez, Y., Petit, M., and Purkus, A. (2018). 'Barriers to entry in frequencyregulation services markets: Review of the status quo and options for improvements', Renewable and Sustainable Energy Reviews, 81, pp. 605-614.

BMWi (2015), 'An electricity market for Germany's energy transition', White Paper by the Federal Ministry for Economic Affairs and Energy, Berlin.

BNEF (2017). 'New Energy Outlook 2017', Bloomberg New Energy Finance.

Burger, S., Chaves-Ávila, J. P., Batlle, C., and Pérez-Arriaga, I. J. (2016). 'The value of aggregators in electricity systems', MIT Center for Energy and Environment Policy Research: Cambridge, MA, USA.

Carmichael, R., Gross, R., and Rhodes, A. (2018). 'Unlocking the Potential of Residential Electricity Consumer Engagement with Demand Response', Imperial College London Energy Future Lab.

CAT (2018). 'Scaling up Climate Action: Key opportunities for transitioning to a zero emissions society', Climate Action Tracker: https://climateactiontracker.org/documents/505/CAT 2018-12-

06 ScalingUp EU FullReport.pdf

CE Delft and Microeconomix (2016), 'Refining Short-Term Electricity Markets to Enhance Flexibility', study on behalf of Agora Energiewende.

CEPA (2014). 'Demand Side Flexibility: The Potential Benefits and State of Play in the European Union', Final Report for ACER.

Chase, A., Gross, R., Heptonstall, P., Jansen, M., Kenefick, M., Parrish, B., and Robson, P., (2017). 'Realising the Potential of Demand-Side Response to 2025: a focus on Small Energy Users', Department for Business, Energy and Industrial Strategy, London.

Couture, T. D., Jacobs, D., Rickerson, W., and Healey, V. (2015). 'The Next Generation of Renewable Electricity Policy. How Rapid Change is Breaking Down Conventional Policy Categories, Clean Energy Solutions Centre, available from NREL: www.nrel.gov/docs/fy15osti/63149.pdf.

Darby, S. J., and McKenna, E. (2012). 'Social implications of residential demand response in cool temperate climates', Energy Policy, 49, pp. 759-769.

de Jong, G., Franz, O., Hermans, P., and Lallemand, M. (2016). 'TSO-DSO data management report', TSO-DSO Project Team, Tech. Rep. 

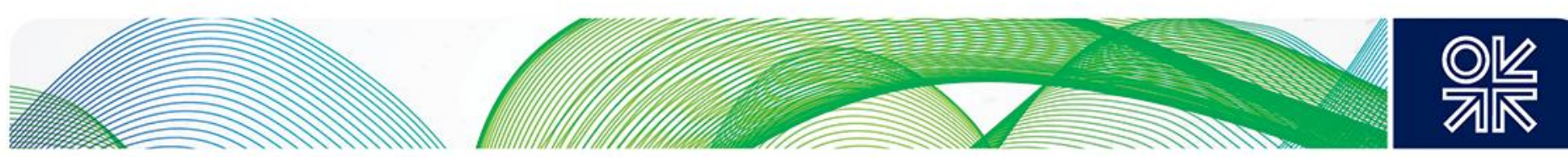

de Jong, J., Hassel, A., Jansen, J., Egenhofer, C., and Xu, Z. (2017). 'Improving the Market for Flexibility in the Electricity Sector' (No. 13093), Centre for European Policy Studies.

DNV GL (2017). 'Flexibility in the power system: A white paper about the need, opportunity and value of flexibility'.

DNV GL (2017a), 'Short Study on Demand Response Activation by Independent Aggregators as Proposed in the Draft Electricity Directive. On behalf of Eurelectric'.

DNV GL (2018). 'Data Analytics in The Electricity Sector, Group Technology \& Research', White Paper 2018.

EC (2014). 'Commission staff working document: Impact Assessment', European Commission, SWD (2014) 15 final.

EC (2015), 'Energy Economic Developments: Investment Perspectives in Electricity Markets', Institutional Paper 003, ISSN 2443-8014, European Commission Directorate-General Economic and Financial Affairs.

EC (2016a). 'Commission Staff Working Document: Impact Assessment', SWD (2016) 410 final.

EC (2018). 'The Strategic Energy Technology (SET) Plan', DG Research and Innovation.

Eckert, V. (2018). 'German Solar Battery Maker Sonnen Qualifies to Provide Grid Services', Reuters: https://uk.reuters.com/article/sonnen-balancingpower-idUKL8N1Y84ZN

EDSO (2018). 'Flexibility in the Energy Transition: A Toolbox for Electricity DSOs'.

Eid, C., Bollinger, L. A., Koirala, B., Scholten, D., Facchinetti, E., Lilliestam, J., and Hakvoort, R. (2016a). 'Market integration of local energy systems: Is local energy management compatible with European regulation for retail competition?' Energy, 114, pp. 913-922.

Eid, C., Codani, P., Perez, Y., Reneses, J., and Hakvoort, R. (2016). 'Managing electric flexibility from Distributed Energy Resources: A review of incentives for market design', Renewable and Sustainable Energy Reviews, 64, pp. 237-247.

ELIA (2017). 'Study on Paid-as-cleared settlement for aFRR and mFRR activated energy'.

ENTSO-E (2018). 'Electricity Balancing in Europe: An Overview of the European Balancing Market and Electricity Balancing Guideline'.

ENTSO-E (2019), 'PowerFacts Europe 2019'.

EY (2019). 'Where does change start if the future is already decided?', EY and Eurelectric.

EnerNOC (2011). 'The Demand Response Baseline', White Paper.

Eurelectric (2018). 'Decarbonisation Pathways'.

ExxonMobil (2018). '2018 Outlook for Energy: A View to 2040'.

Field, K. (2018). 'Sonnen Edges into the Grid Services Market in Germany', CleanTechnica: https://cleantechnica.com/2018/12/11/sonnen-edges-into-the-grid-services-market-in-germany/

Frunt, J. (2011). 'Analysis of balancing requirements in future sustainable and reliable power systems,' Eindhoven University of Technology.

Gangale, F., Vasiljevska, J., Covrig, C. F., Mengolini, A., and Fulli, G. (2017). 'Smart grid projects outlook 2017', Joint Research Centre of the European Commission: Petten, The Netherlands.

Gerard, H., Puente, E. I. R., and Six, D. (2018). 'Coordination between transmission and distribution system operators in the electricity sector: A conceptual framework,' Utilities Policy, 50, pp. 40-48. 

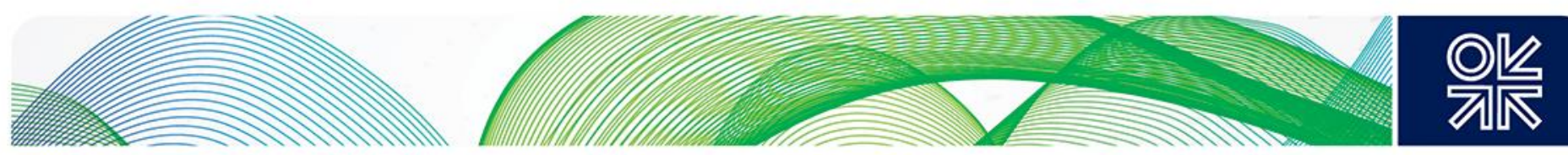

Ghazvini, M. A. F., Soares, J., Abrishambaf, O., Castro, R., and Vale, Z. (2017). 'Demand response implementation in smart households,' Energy and Buildings, 143, pp. 129-148.

Glachant. J. M. and Rossetto. N., (2018). 'The Digital World Knocks at Electricity's Door: Six Building Blocks to Understand Why', Florence School of Regulation, European University Institute.

Goldenberg, C., Dyson. M. and Mastrs, H. (2018), 'Demand Flexibility: the key to enable a low-cost, low-carbon grid', Rocky Mountain Institute.

Good, N., Ellis, K. A., and Mancarella, P. (2017). 'Review and classification of barriers and enablers of demand response in the smart grid', Renewable and Sustainable Energy Reviews, 72, pp. 57-72.

Hadush, S. Y., and Meeus, L., (2017). 'DSO-TSO Cooperation Issues and Solutions for Distribution Grid Congestion Management', Florence School of Regulation, European University Institute.

Haney, A. B., Jamasb, T., Platchkov, L. M., and Pollitt, M. G. (2010). 'Demand-side management strategies and the residential sector: lessons from international experience', EPRG working paper, Cambridge Universtiy Press.

Hans, H. and Reek, W., (2018), 'Flexibility Platforms', USEF White Paper.

Harris, C. (2005). Electricity markets: pricing, structures and economics, John Wiley and Sons, Ltd.

Healy, S., and MacGill, I. (2012). 'From smart grid to smart energy use', in Smart Grid (pp. 29-59).

Hesser, T., and Succar, S. (2012). 'Renewables integration through direct load control and demand response', in Smart Grid (pp. 209-233).

Hirth, L. (2013). 'The market value of variable renewables: The effect of solar wind power variability on their relative price', Energy economics, 38, 218-236.

Hirth, L., Ueckerdt, F., and Edenhofer, O. (2016). 'Why wind is not coal: on the economics of electricity generation', The Energy Journal, 37(3), 1-27.

Hogan, W. W. (2015), 'Electricity Market Design, Energy and Capacity Markets and Resource Adequacy', EUCl Conference: https://sites.hks.harvard.edu/fs/whogan/Hogan EUCl 090115.pdf

Holmberg, P., and Lazarczyk, E. (2012). Congestion management in electricity networks: Nodal, zonal and discriminatory pricing. IFN Working Paper No.915.

Holmberg, D. G., Hardin, D., and Koch, E. (2013). Towards demand response measurement and verification standards. National Institute of Standards and Technology.

IEA (2017). 'Tracking Clean Energy Progress: 2017', International Energy Agency: https://www.iea.org/etp/tracking2017/.

IEA (2017a). 'World Energy Outlook 2017', International Energy Agency: https://www.iea.org/weo2017/.

IEA (2017b). 'Digitalization and Energy 2017', International Energy Agency: https://www.iea.org/digital/.

IEA (2018). 'Status of Power System Transformation 2018: Advanced Power Plant Flexibility', International Energy Agency.

IEA (2018a). 'World Energy Outlook 2018', International Energy Agency: https://www.iea.org/weo2018/.

IEA (2018b). 'Energy Efficiency 2018: Analysis and Outlooks to 2040', International Energy Agency.

IEA and NEA (2015). 'Projected Costs of Generating Electricity', Organization for Economic Cooperation and Development.

IEC (2012), 'Grid Integration of Large-capacity Renewable Energy Sources and Use of Large-Capacity Electrical Energy Storage', International Electrotechnical Commission White Paper. 

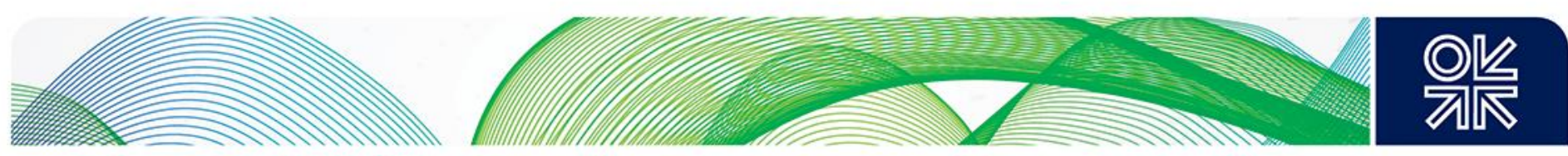

IRENA, IEA and REN21 (2018), 'Renewable Energy Policies in Time of Transition': http://www.irena.org/publications/2018/Apr/Renewable-energy-policies-in-a-time-of-transition

Keay, M., and Robinson, D. (2019), 'The Limits of Auction: reflections on the role of central purchaser auctions for long-term commitments in electricity system', OIES, April 2019: https://www.oxfordenergy.org/publications/limits-auctions-reflections-role-central-purchaser-auctionslong-term-commitments-electricity-systems/?v=79cba1185463.

Klessmann, C., Nabe, C., and Burges, K. (2008). 'Pros and cons of exposing renewables to electricity market risks - A comparison of the market integration approaches in Germany, Spain, and the UK', Energy Policy, 36(10), pp. 3646-3661.

Lavoine, O., (2018), 'Thoughts on an Electricity System and Grid Paradigm Shift in Response to the EU Energy Transition and the Clean Energy Package', Florence School of Regulation, European University Institute.

MacDonald, M. (2013). Impact Assessment on European Electricity Balancing Market.

Mandatova, P., and Mikhailova, O. (2014). 'Flexibility and Aggregation: Requirements for their interaction in the market', https://www.usef.energy/app/uploads/2016/12/EURELECTRIC-Flexibility-and-Aggregation-jan2014.pdf.

Marroquin, M., Madina, C., and Pardo, M., (2018). 'Design and Simulation of Novel Demand Response Management Systems under Enhanced TSO-DSO Interaction', Electricity Europe.

Mauritzen, J. (2013). 'Now or Later? Trading wind power closer to real-time and how poorly designed subsidies lead to higher balancing costs', NHH Dept. of Business and Management Science Discussion Paper No. 2013/1. Available at SSRN: https://ssrn.com/abstract=2294361 or http://dx.doi.org/10.2139/ssrn.2294361.

Mckinsey (2018). 'The New Rules of Competition in Energy Storage': https://www.mckinsey.com/industries/electric-power-and-natural-gas/our-insights/the-new-rules-ofcompetition-in-energy-storage

Meeus,L., and Nouicer, A. (2018). 'The EU Clean Energy Package: Technical Report', Florence School of Regulation, European University Institute.

Meeus, L., and Hadush, S. (2016). 'The emerging regulatory practice for new businesses related to distribution grids', Florence School of Regulation, European University Institute.

Merino, J., Gómez, I., Turienzo, E., and Madina, C. (2016). 'Ancillary service provision by RES and DSM connected at distribution level in the future power system', SmartNet project D, 1, 1.

Migliavacca, G., Rossi, M., Six, D., Džamarija, M., Horsmanheimo, S., Madina, C., and Morales, J. M. (2017). 'SmartNet: H2020 project analysing TSO-DSO interaction to enable ancillary services provision from distribution networks', CIRED-Open Access Proceedings Journal, 2017(1), pp. 1998-2002.

Minniti, S., Haque, N., Nguyen, P., and Pemen, G. (2018). 'Local markets for flexibility trading: key stages and enablers', Energies, 11(11), p. 3074.

Mohrhauer, T. (2016). 'Comparison of Nodal, Zonal and Hybrid Market Structures with Respect to Operating Cost and Redispatch Volumes', Doctoral dissertation, EEH-Power Systems Laboratory, Swiss Federal Institute of Technology.

Newbery, D., Pollitt, M., Ritz, R., and Strielkowski, W. (2017). 'Market design for a high-renewables European electricity system', EPRG working paper, Cambridge: Cambridge University Press. 

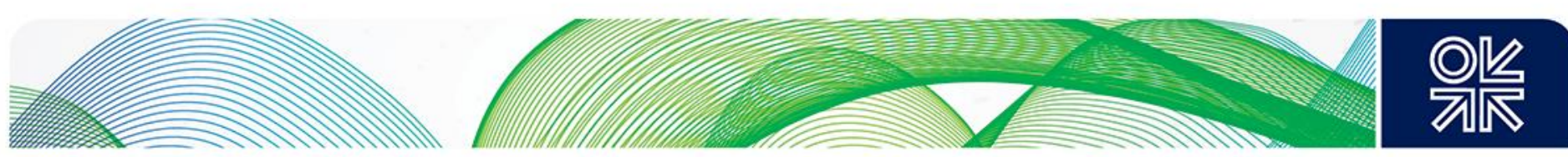

NVE (2016). 'Status of NVE's work on Network Tariffs in the Electricity Distribution System': publikasjoner.nve.no/rapport/2016/rapport2016_62.pdf.

Ocker, F. (2017). 'Design and performance of European balancing power auctions', in 2017 14th International Conference on the European Energy Market (EEM), pp. 1-6, IEEE.

Ocker, F., Braun, S., and Will, C. (2016). 'Design of European balancing power markets,' in 2016 13th International Conference on the European Energy Market (EEM), pp. 1-6, IEEE.

Paetz, A. G., Dütschke, E., and Fichtner, W. (2012). 'Smart homes as a means to sustainable energy consumption: A study of consumer perceptions', Journal of consumer policy, 35(1), pp 23-41.

Papavasiliou, A. (2018). 'Analysis of distribution locational marginal prices', IEEE Transactions on Smart Grid, 9(5), pp. 4872-4882.

Paterakis, N. G., Erdinç, O., and Catalão, J. P. (2017). 'An overview of Demand Response: Keyelements and international experience', Renewable and Sustainable Energy Reviews, 69, pp. 871-891.

Pollitt, M., and Chyong, C. K. (2018). 'Europe's Electricity Market Design: 2030 and Beyond', Centre on Regulation in Europe: https://www.cerre.eu/publications/europes-electricity-market-design-2030-andbeyond.

Poncela, M., Purvins, A., and Chondrogiannis, S. (2018). 'Pan-European analysis on power system flexibility', Energies, 11(7), p. 1765.

Poudineh, R., and Jamasb, T. (2014). 'Distributed generation, storage, demand response and energy efficiency as alternatives to grid capacity enhancement', Energy Policy, 67, pp. 222-231.

Redl, C. (2018). 'A Word on Flexibility: The German Energiewende in Practice: how the electricity market manages flexibility challenges when the shares of wind and PV are high', Agora: https://www.agora-energiewende.de/en/publications/a-word-on-flexibility/.

Rhys, J., (2016) 'A two-tire energy market for the 21 https://www.oxfordmartin.ox.ac.uk/opinion/view/355

Richter, L. L., and Pollitt, M. G. (2016). 'Which smart electricity service contracts will consumers accept? The demand for compensation in a platform market', EPRG working paper, Cambridge: Cambridge University Press.

Rossetto, N. (2017), 'Design the Electricity Market(s) of The Future', Florence School of Regulation, European University Institute.

Scherer, M., Haubensak, O., and Staake, T. (2015). 'Assessing distorted trading incentives of balance responsible parties based on the example of the Swiss power system', Energy Policy, 86, pp. 792-801.

Schittekatte, T.,and Meeus,L (2018a). 'Introduction to Network Tariffs and Network Codes for Consumers, Prosumers and Energy Communities', Florence School of Regulation, European University Institute.

Schittekatte. T. and Meeus. L., (2018b), 'Limits of Traditional Distribution Network Tariff Design and Options to Move Beyond', Florence School of Regulation, European University Institute.

Schittekatte. T. and Meeus. L., (2019), 'Flexibility Markets: Q\&A with Project Pioneers', Florence School of Regulation, European University Institute.

SEDC (2017). 'Explicit Demand Response in Europe', Mapping the Markets 2017: http://www.smarten.eu.

Sia Partners (2014). 'Demand Response: A Study of its Potential in Europe', Insight Energy and Environment. 

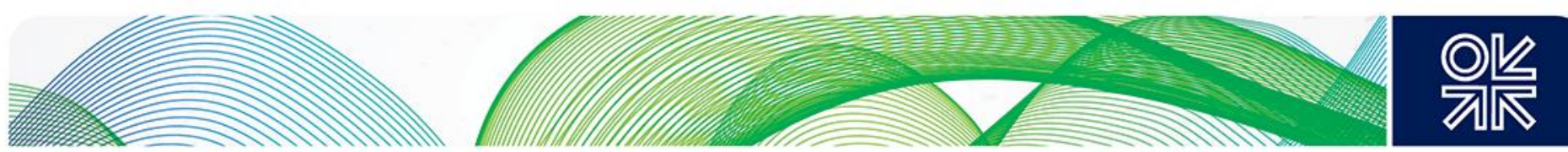

smartEn (2018a). 'The smartEn Map: European Balancing Market Edition': http://www.smarten.eu/wpcontent/uploads/2018/11/the smarten map 2018.pdf

TenneT (2019), 'Dutch grid operators launch GOPACS: a smart solution to reduce congestion in the electricity grid': $\quad$ https://www.tennet.eu/news/detail/dutch-grid-operators-launch-gopacs-a-smartsolution-to-reduce-congestion-in-the-electricity-grid/

Ueckerdt, F., Hirth, L., Luderer, G., and Edenhofer, O. (2013). 'System LCOE: What are the costs of variable renewables?', Energy, 63, pp. 61-75.

USEF (2015), 'USEF: The Framework https://www.usef.energy/app/uploads/2016/12/USEF TheFrameworkExplained-

18nov15.pdf\#popup overlay1

van der Veen, R. A., and Hakvoort, R. A. (2016). 'The electricity balancing market: Exploring the design challenge', Utilities Policy, 43, pp. 186-194.

Verhaegen, R., and Dierckxsens, C. (2016). 'Existing business models for renewable energy aggregators', BestRES: Best practices and implementation of innovative business models for Renewable Energy aggregators: http://bestres.eu/.

Verhaegen, R., and Dierckxsens, C. (2017). 'Review of Future Electricity Market Options', BestRES: Best practices and implementation of innovative business models for Renewable Energy aggregators: http://bestres.eu/

Wargers, A., Kula, Jan., Obregon, F. O.and Rubio, D. (2018). 'European Distribution System Operators for Smart Grids. Smart charging: Integrating a large widespread of electric cars in electricity distribution grids.' EDSO Technology Committee.

WEC (2016). 'Word Energy Resources E-Storage 2016', World Energy Council.

WindEurope (2018). 'Wind in Power 2017: Annual Combined Onshore and Offshore Wind Energy Statistics'.

Zancanella, P. and Bertoldi, P. (2017), 'Why is Demand Response not Implemented in the EU? Status of Demand Response and Recommendations to allow Demand Response to be fully Integrated in Energy Markets', ECEEE 2017 Summary Study. 